Nutrient Uptake Estimates for Woody Species as Described by the NST 3.0, SSAND, and PCATS Mechanistic Nutrient Uptake Models

\author{
Wen Lin \\ Thesis submitted to the faculty of the \\ Virginia Polytechnic Institute and State University \\ in partial fulfillment of the requirements for the degree of \\ Master of Science \\ In \\ Forestry
}

J. Michael Kelly, Chair

Thomas R. Fox

John R. Seiler

July 17, 2009

Blacksburg, VA

Keywords: model comparison, multiple dimensional sensitivity analysis, soil moisture, $\mathrm{I}_{\max }$ 
Nutrient Uptake Estimates for Woody Species as Described by the NST 3.0, SSAND, and PCATS Mechanistic Nutrient Uptake Models

Wen Lin

\begin{abstract}
With the advent of the personal computer, mechanistic nutrient uptake models have become widely used as research and teaching tools in plant and soil science. Three models NST 3.0, SSAND, and PCATS have evolved to represent the current state of the art. There are two major categories of mechanistic models, transient state models with numerical solutions and steady state models. NST 3.0 belongs to the former model type, while SSAND and PCATS belong to the latter. NST 3.0 has been used extensively in crop research but has not been used with woody species. Only a few studies using SSAND and PCATS are available. To better understand the similarities and differences of these three models, it would be useful to compare model predictions with experimental observations using multiple datasets from the literature to represent various situations for woody species. Therefore, the objectives of this study are to: (i) compare the predictions of uptake by the NST 3.0, SSAND, and PCATS models for a suite of nutrients against experimentally measured values, (ii) compare the behavior of the three models using a one dimensional sensitivity analysis; and (iii) compare and contrast the behavior of NST 3.0 and SSAND using a multiple dimensional sensitivity analysis approach. Predictions of nutrient uptake by the three models when run with a common data set were diverse, indicating a need for a reexamination of model structure. The failure of many of the predictions to match observations indicates the need for further studies which produce representative datasets so that the predictive accuracy of each model can be evaluated. Both types of sensitivity analyses suggest that the effect of soil moisture on simulation can be influential when nutrient concentration in the soil solution $\left(\mathrm{C}_{\mathrm{Li}}\right)$ is low. One dimensional sensitivity analysis also revealed that $\mathrm{I}_{\max }$ negatively influenced the uptake estimates from the SSAND and PCATS models. Further analysis indicates that this counter intuitive response of $I_{\max }$ is probably related to low soil nutrient supply. The predictions of SSAND under low-nutrient-supply scenarios are generally lower than those of NST 3.0. We suspect that both of these results are artifacts of the steady state models and further studies to improve them, such as incorporating important rhizospheric effects, are needed if they are to be used successfully for the longer growth periods and lower soil nutrient supply situations more typical of woody species.
\end{abstract}




\section{Acknowledgements}

I would like to express thanks to committee members Dr. J. M. Kelly, Dr. T. R. Fox, and Dr. J. R. Seiler for their valuable help into this work. I am honored to have them serve on my committee and I learned a lot from them. I would also like to express thanks to Dr. C. A. Copenheaver. She is a great teacher and always helpful. Many thanks to the professors of Virginia Tech that showed me by their actions what an ideal scientific life looks like.

I own my appreciation to my family and friends, who supported and encouraged me over the years. Finally I want to thank my best friend, Xiaowei Tang, without whom my life in a foreign country would be much harder. 


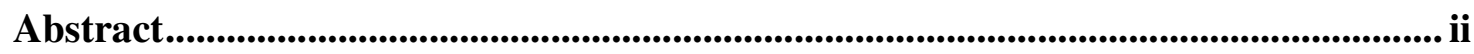

Acknowledgements ............................................................................................................................. iii

Table of Contents ........................................................................................................................... iv

List of Tables ...................................................................................................................... vi

List of Figures......................................................................................................................................... vii

Chapter I. INTRODUCTION_............................................................................................ 1

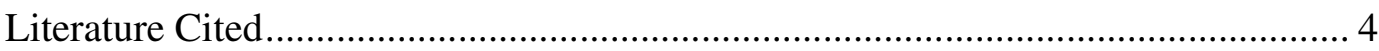

Chapter II. LITERATURE REVIEW ................................................................6 6

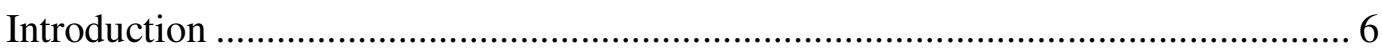

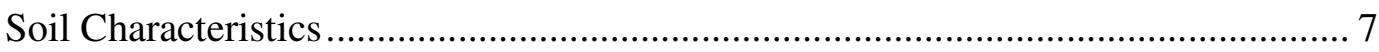

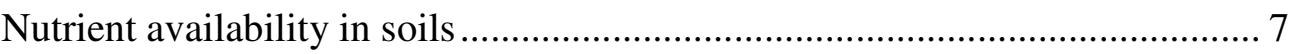

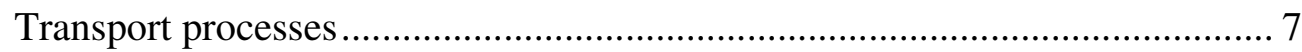

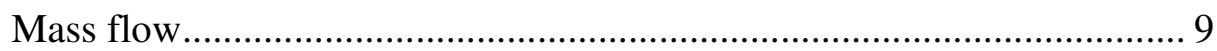

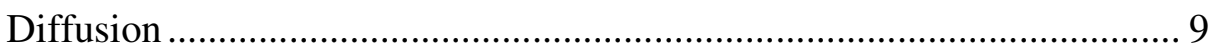

Simultaneous mass flow and diffusion ................................................. 10

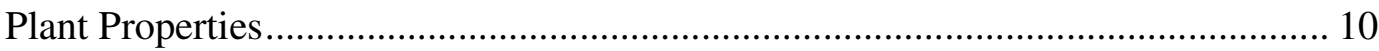

Root morphology and growth ............................................................. 10

Nutrient uptake kinetics ................................................................................ 11

Nutrient uptake mechanisms................................................................ 11

Modeling nutrient uptake kinetics ......................................................... 12

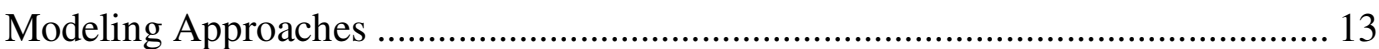

The basic principles of NUTRIENT UPTAKE and NST 3.0 ...................... 13

The basic principles of COMP8, SSAND, and PCATS.................................. 14

Assumptions for the mechanistic models.................................................. 16

Comparison of the two major categories of mechanistic models ................... 17

Current study on NST 3.0, SSAND, and PCATS ......................................... 18

Sensitivity Analysis of Mechanistic Nutrient Uptake Models ................................ 19

Nutrient Uptake Modeling of Woody Species ........................................................ 20

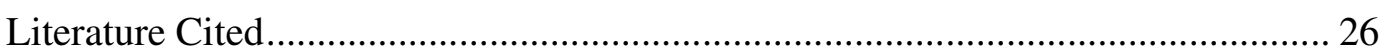

Chapter III. NUTRIENT UPTAKE ESTIMATES FOR WOODY SPECIES AS DESCRIBED BY THE NST 3.0, SSAND, AND PCATS MECHANISTIC NUTRIENT UPTAKE MODELS ............................................................................. 31

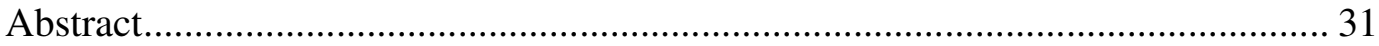

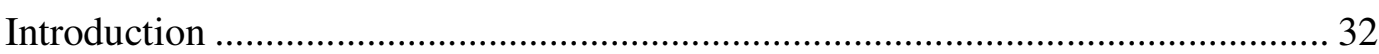




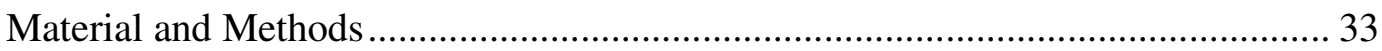

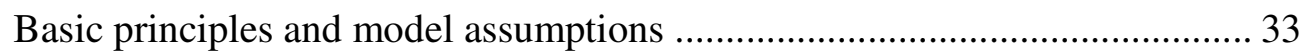

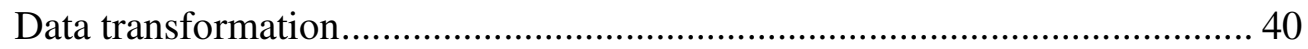

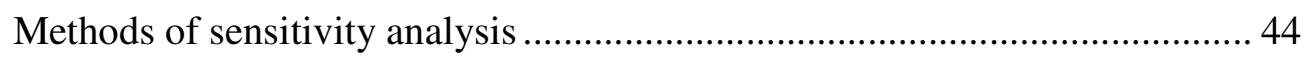

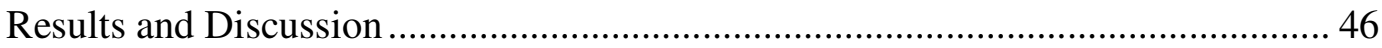

Calculation of uptake using data taken from the literature ............................ 46

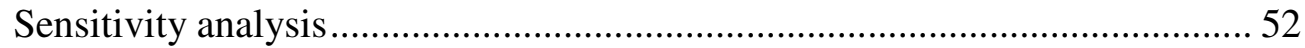

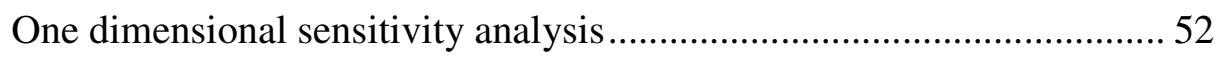

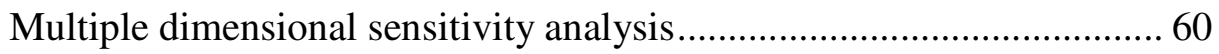

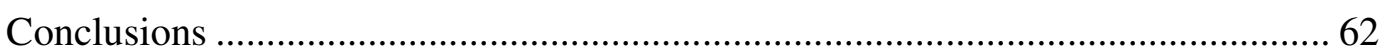

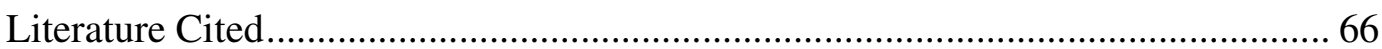




\section{List of Tables}

Table 1: List of symbols and definitions used in mechanistic nutrient uptake model equations.

Table 2: Nutrient uptake kinetic parameters for a variety of woody species taken from the literature. 22

Table 3: Soil supply parameters from studies of a variety of woody species. 23

Table 4: Root growth parameters from a variety of woody species and the mean water flux at the root surface taken from the literature.

Table 5: List of symbols and definitions used in the NST 3.0, SSAND, and PCATS mechanistic nutrient uptake model equations.

Table 6: Parameter values for loblolly pine and red maple based on observations reported by Kelly et al. (1992) and Kelly et al. (2001) used for NST 3.0, SSAND and PCATS simulations.

Table 7: Parameter values for hybrid poplar based on observations reported by Kelly and Ericsson (2003) used for NST 3.0, SSAND and PCATS simulations.

Table 8: Literature values for soil moisture $(\theta)$ taken from field, nursery, and greenhouse studies of loblolly and slash pine.

Table 9: Literature values for potassium concentration in soil solution $\left(\mathrm{C}_{\mathrm{Li}}\right)$ taken from field, nursery, and greenhouse studies of loblolly and slash pine.

Table 10: Literature values of root growth rate $(\mathrm{k})$ taken from field, nursery, and greenhouse studies of loblolly and slash pine.

Table 11: Observed uptake of $\mathrm{NO}_{3}-\mathrm{N}, \mathrm{P}$, and $\mathrm{K}$ compared to simulated uptake as predicted by NST 3.0, SSAND, and PCATS using data from Kelly et al. (1992), Kelly et al. (2001), and Kelly and Ericsson (2003). The percentages represent the degree of correspondence between the simulated and observed uptake value. 


\section{List of Figures}

Figure 1: Comparison of predicted potassium uptake by the NST 3.0, SSAND, and PCATS models and observed potassium uptake using data from the studies by Kelly et al. (1992), Kelly et al. (2001), and Kelly and Ericsson (2003).

Figure 2: Comparison of predicted nitrate uptake by the NST 3.0, SSAND, and PCATS models and observed nitrate uptake using data from the studies by Kelly et al. (1992), Kelly et al. (2001), and Kelly and Ericsson (2003).

Figure 3: Comparison of predicted phosphorus uptake by the NST 3.0, SSAND, and PCATS models and observed phosphorus uptake using data from the studies by Kelly et al. (1992), Kelly et al. (2001), and Kelly and Ericsson (2003).

Figure 4: One dimensional sensitivity analysis using SSAND with potassium uptake data for loblolly pine seedlings from Kelly et al. (1992) and the diffusion coefficient of potassium in water at $25^{\circ} \mathrm{C}$ taken from the Parsons (1959).

Figure 5: One dimensional sensitivity analysis using PCATS with potassium uptake data for loblolly pine seedlings from Kelly et al. (1992) and the diffusion coefficient of potassium in water at $25^{\circ} \mathrm{C}$ taken from the Parsons (1959).

Figure 6: One dimensional sensitivity analysis using NST 3.0 with potassium uptake data for loblolly pine seedlings from Kelly et al. (1992) and the diffusion coefficient of potassium in water at $25^{\circ} \mathrm{C}$ taken from the Parsons (1959).

Figure 7: Simulated uptake by SSAND and NST 3.0 at five levels of $I_{\max }$ and three levels of $\mathrm{C}_{\mathrm{Li}}$. For these simulations root growth rate and volumetric soil moisture have been set to $39.3 \mathrm{~cm}$ day $^{-1}$ and 0.4 respectively. Other parameter values remained as listed in Table 6 for loblolly pine (Kelly et al. 1992).

Figure 8: Response surface from a multiple dimensional sensitivity analysis of SSAND and NST 3.0 using five levels of potassium concentration in the soil solution $\left(\mathrm{C}_{\mathrm{Li}}\right)$, five levels of volumetric soil moisture $(\theta)$, and five levels of root growth rate $(\mathrm{k})$. Other parameter values remained as listed in Table 6 for loblolly pine (Kelly et al. 1992). The unit of simulated uptake is $\mu$ mol.

Figure 9: Response surface from a multiple dimensional sensitivity analysis of SSAND and NST 3.0 using two levels of potassium concentration in the soil solution $\left(\mathrm{C}_{\mathrm{Li}}\right)$, five levels of volumetric soil moisture $(\theta)$, and five levels of root growth rate $(\mathrm{k})$ with $\mathrm{cm}$ day $^{-1}$ as the units. Other parameter values remained as listed in Table 6 for loblolly pine (Kelly et al. 1992).

Figure 10: Simulated potassium uptake by SSAND and NST 3.0 with data taken from Kelly et al. (1992). The simulation was conducted with nutrient concentration in the soil solution $\left(\mathrm{C}_{\mathrm{Li}}\right)$ changing from 0.028 to $4.284 \mu \mathrm{mol} \mathrm{ml}{ }^{-1}$ while keeping other parameters unchanged. 


\section{Chapter I. INTRODUCTION}

Influenced by many chemical, physical, and physiological factors, plant nutrient uptake is a very complex process (Barber 1995). A mechanistic nutrient uptake model simulates this process using mechanistic or empirical equations based on basic mechanisms. Based on the seminal efforts by Nye and Marriot (1969) and Baldwin et al. (1973), and advanced by the subsequent work of Claassen and Barber (1976), Nye and Tinker (1977), Barber and Cushman (1981), Claassen et al. (1986), Smethurst and Comerford (1993), Yanai (1994), Smethurst et al. (2004), and Comerford et al. (2006), mechanistic models were developed for the personal computer that allows nutrient uptake by plant roots to be calculated. These models take into consideration the competition between roots within a specified time, as well as the size and growth of the roots, the kinetics of nutrient uptake, and the supply of nutrients from the soil to the root surface (Barber 1995). Research on several crop species has demonstrated that the predictions of these mechanistic models generally match the observed uptake under situations in which the soil and plant conditions are relatively constant (Barber 1995; Tinker and Nye 2000). Results with woody species have been more variable (Gillespie and Pope 1990; Van Rees et al. 1990; Smethurst and Comerford 1993).

Validated mechanistic models allow data interpolation and extrapolation (Claassen and Steingrobe 1999), and are able to provide predictions under various situations, which may avoid the need for costly field trials (Barber 1995; Tinker and Nye 2000). They can also be used to calculate values that are difficult to determine experimentally (Claassen and Steingrobe 1999) in addition to revealing the factors that have the greatest influence on the nutrient uptake processes (Barber 1995).

NST 1.0, SSAND, and PCATS are three mechanistic nutrient uptake models which were presented in 1986, 2000, and 2004, respectively (Li and Comerford 2000; Smethurst et al. 2004; Claassen et al. 1986). NST 3.0 is the improved version of NST 1.0, which was developed in 1990s and not published in a journal (Claassen, N. Personal communication. 2009, 31 July). NST models are based largely on the Barber-Cushman model (Claassen et al. 1986), and belong to transient state models using a numerical 
solution. SSAND and PCATS are steady state models based on the key equations developed by Baldwin et al. (1973) and Nye and Tinker (1977), with the assumption that the "concentration profile around the root can be considered to be in a steady state" (Yanai 1994). Compared to SSAND, PCATS further simplifies calculation by running on a fixed daily time-step (Smethurst et al. 2004). Transient state models with a numerical solution are generally considered to be more accurate than steady state models (Smethurst and Comerford 1993; Yanai 1994). However, steady state models can be constructed to allow parameters to change during simulation and thus are able to respond to real-time changes in parameters as well as allowing for the feedback between soil and plant processes during simulation (Yanai 1994).

One way to evaluate the models is by comparing model predictions with measured values. A second way is to use sensitivity analysis. The traditional way to conduct a sensitivity analysis in the modeling context is to vary a single input parameter in a model while keeping the others constant (Silberbush and Barber 1983). By plotting the change ratio of the parameters compared to their original values on the horizontal axis, and that of the predicted uptake to the original prediction on the vertical axis, it is possible to evaluate the importance of each parameter by the slopes of the lines on the graph (Silberbush and Barber 1983). As Williams and Yanai (1996) have suggested, this method can be called a one dimensional sensitivity analysis. However, because the relative importance of parameters defined this way can depend strongly on the values of the other parameters, Williams and Yanai (1996) developed a multiple dimensional sensitivity analysis in order to study model behavior across a broad range of possible parameter values.

In their approach to multiple dimensional sensitivity analysis, Williams and Yanai (1996) utilized data taken from the literature for both crop and tree species. They identified four factors as the most influential parameters controlling uptake per unit length of root: (i) the average dissolved nutrient concentration $\left(\mathrm{C}_{\mathrm{av}}\right)$, (ii) the maximal rate of nutrient uptake $\left(\mathrm{I}_{\max }\right)$, (iii) the effective diffusion coefficient $\left(\mathrm{D}_{\mathrm{e}}\right)$, and (iv) the root radius $\left(r_{0}\right)$. However, as noted by Fitter (2002), differences between the roots of woody and herbaceous species can be important, especially in terms of root radius and 
suberization. Both of these differences could influence estimated nutrient uptake. Also, Williams and Yanai (1996) used a simplified model whose behavior may be different from the NST 3.0, SSAND, and PCats models. For example, the study by Van Rees et al. (1990) on slash pine (Pinus elliottii var. elliottii) and that of Kelly et al. (1992) on loblolly pine (Pinus taeda) indicate that the influence of root growth rate $(\mathrm{k})$ is prominent in the sensitivity analysis by the NUTRIENT UPTAKE model by Oates and Barber (1987).

Most studies to date have focused on tests of individual models. The number of studies using SSAND and PCATS are limited. NST 3.0 has been widely used but only with crop species. Therefore, using a common data set to compare the predictions of nutrient uptake by NST 3.0, SSAND, and PCATS against observed values combined with the use of sensitivity analysis would help us better understand model behaviors under various situations and provide useful information for future model development.

Therefore, the objectives of this study are to: (i) compare the predictions of uptake by the NST 3.0, SSAND, and PCATS models for a suite of nutrients against experimentally measured values, (ii) compare the behavior of the three models using a one dimensional sensitivity analysis; and (iii) compare and contrast the behavior of NST 3.0 and SSAND using the multiple dimensional sensitivity analysis approach of Williams and Yanai (1996). Common data sets, based on literature values only taken from studies of woody species, will be used for these comparisons. 


\section{Literature Cited}

Baldwin, J. P., P. H. Nye and P. B. Tinker. 1973. Uptake of solutes by multiple root systems from soil III - a model for calculating the solute uptake by a randomly dispersed root system developing in a finite volume of soil. Plant and Soil 38: 621635.

Barber, S. A. 1995. Soil nutrient bioavailability: a mechanistic approach. 2nd edition. John Wiley \& Sons, Inc., New York.

Barber, S. A. and J. H. Cushman 1981. Nitrogen uptake model for agronomic crops. p. 382-409 In I. K. Iskandar (ed.). Modeling waste water renovation-land treatment. Wiley-Interscience, New York.

Claassen, N. and S. A. Barber. 1976. Simulation model for nutrient uptake from soil by a growing plant root system. Agronomy Journal 68: 961-964.

Claassen, N. and B. Steingrobe 1999. Mechanistic simulation models for a better understanding of nutrient uptake from soil. p. 327-367 In Z. Rengel (ed.). Mineral nutrition of crops: fundamental mechanisms and implications. Food Products Press, New York.

Claassen, N., K. M. Syring and A. Jungk. 1986. Verification of a mathematical-model by simulating potassium uptake from soil. Plant and Soil 95: 209-220.

Comerford, N. B., W. P. Cropper, Jr., L. Hua, P. J. Smethurst, K. C. J. Van Rees, E. J. Jokela and F. Adams. 2006. Soil Supply and Nutrient Demand (SSAND): a general nutrient uptake model and an example of its application to forest management. Canadian Journal of Soil Science 86: 655-673.

Fitter, A. 2002. Characteristics and functions of root systems. p. 15-32 In Y. Waisel, A. Eshel and U. Kafkafi (ed.). Plant roots: the hidden half. Marcel Dekker, Inc., New York.

Gillespie, A. R. and P. E. Pope. 1990. Rhizosphere acidification increases phosphorus recovery of black locust: II. Model predictions and measured recovery. Soil Science Society of America Journal 54: 538-541.

Li, H. and N. B. Comerford. 2000. SSAND Version 1.0, Release 1.06 (10-8-2001) User's Guide. University of Florida. Gainesville, FL.

Nye, P. H. and F. H. C. Marriott. 1969. A theoretical study of the distribution of substances around roots resulting from simultaneous diffusion and mass flow. Plant and Soil 30: 459-472.

Nye, P. H. and P. B. Tinker. 1977. Solute movement in the soil-root system. University of California Press, Berkeley. 
Oates, K. and S. A. Barber. 1987. NUTRIENT UPTAKE: a microcomputer program to predict nutrient absorption from soil by roots. Journal of Agronomic Education 16: 65-68.

Samal, D. 2007. Potassium Uptake Efficiency Mechanisms and Root Exudates of Different Crop Species. Ph.D. Dissertation Georg-August-University Göttingen, Germany.

Silberbush, M. and S. A. Barber. 1983. Sensitivity of simulated phosphorus uptake to parameters used by a mechanistic-mathematical model. Plant and Soil 74: 93-100.

Smethurst, P. J. and N. B. Comerford. 1993. Simulating nutrient uptake by single or competing and contrasting root systems. Soil Science Society of America Journal 57: $1361-1367$.

Smethurst, P. J., D. S. Mendham, M. Battaglia and R. Misra. 2004. Simultaneous prediction of nitrogen and phosphorus dynamics in a Eucalyptus nitens plantation using linked CABALA and PCATS models. p. 565-569 In N. M. G. Borralho (ed.) Eucalyptus in a changing world. Proceedings of an International conference of the WP2.08.03 on silviculture and improvement of eucalypts, Aveiro, Portugal, 11-15 October 2004. IUFRO, Aveiro, Portugal.

Tinker, P. B. and P. H. Nye. 2000. Solute movement in the rhizosphere. Oxford University Press, New York.

Van Rees, K. C. J., N. B. Comerford and W. W. Mcfee. 1990. Modelling potassium uptake by slash pine seedlings from low-potassium-supplying soils. Soil Science Society of America Journal 54: 1413-1421.

Williams, M. and R. D. Yanai. 1996. Multi-dimensional sensitivity analysis and ecological implications of a nutrient uptake model. Plant and Soil 180: 311-324.

Yanai, R. D. 1994. A steady-state model of nutrient uptake accounting for newly grown roots. Soil Science Society of America Journal 58: 1562-1571. 


\section{Chapter II. LITERATURE REVIEW}

\section{Introduction}

Two general categories of nutrient uptake models, empirical and mechanistic models have been developed to study nutrient uptake by plant roots (Rengel 1993). Empirical models are based mainly on regressions as well as statistical means, often for practical use (Claassen and Steingrobe 1999). Mechanistic models, on the other hand, require an understanding of the mechanisms and a quantitative description of the phenomena (Rengel 1993). Mechanistic models are therefore useful to test the correctness of our knowledge of the phenomena (Claassen and Steingrobe 1999). Extrapolation of a verified mechanistic model is thus more reliable than that of an empirical model (Claassen and Steingrobe 1999). Another scientific application is the calculation of parameters that are difficult to obtain for either technical or economic reasons (Claassen and Steingrobe 1999). Model runs can also be used to identify topics that warrant further field or laboratory study. Finally, we can improve our understanding of the phenomena by exploring model behavior without conducting field trials (Barber 1995; Claassen and Steingrobe 1999).

Nutrient uptake by plant roots involves interdisciplinary studies: soil chemistry, soil physics, and plant physiology (Barber 1995). The typical mechanistic nutrient uptake model describes the supply of nutrients from bulk soil to root surfaces, root growth and morphology, and root uptake kinetics (Barber 1995).

The modeling of nutrient uptake started in the early 1960s. Bouldin (1961) and Olsen et al. (1962) proposed mathematical models to simulate diffusion of solutes through soils, which were used to explain phosphate movement and uptake. Nye and Spiers (1964) subsequently developed the partial differential equations used to describe simultaneous mass flow and diffusion for nutrient uptake by a unit length of root. Nye and Marriot (1969) defined boundary conditions for the equations and solved them numerically, while Baldwin et al. (1973), on the other hand, solved the equations analytically with steady state approximations. Their work became the foundation for mechanistic nutrient uptake models. Building on this base Claassen and Barber (1976), Nye and Tinker (1977), Barber and Cushman (1981), Claassen et al. (1986), Smethurst 
and Comerford (1993b), Yanai (1994), Smethurst et al. (2004), and Comerford et al. (2006) proposed model revisions to cover the major sub-processes of nutrient uptake and to accommodate a variety of additional conditions. Current models have been successfully used in many areas of plant nutrition research.

In this review the soil and plant properties will be discussed first, followed by a mathematical description of the models and the use of sensitivity analysis to identify key parameters. Finally, a review of studies that have applied mechanistic nutrient uptake models to study woody species is presented. Because many parameters are involved, the symbols and their definitions are listed in Table 1.

\section{Soil Characteristics}

Nutrient availability in soils

Soil is a highly complex and heterogeneous system with many different components that provide plants with water and nutrients. Nutrients exist in the soil in gaseous, liquid, and solid forms. In this review only nutrients in liquid and solid forms will be discussed. Barber (1995) defined an available nutrient as "the nutrient present in a pool of ions in the soil and can move to the plant root during plant growth if the root is close enough". In the early development of mechanistic models, available nutrients were restricted to inorganic forms to simplify calculation (Barber 1995), but latter models such as SSAND are able to include nutrient from organic forms such as the mineralization of nitrogen (Comerford et al. 2006).

\section{Transport processes}

Interception, mass flow, and diffusion are the three components of nutrient movement to the root surface (Marschner 1995). Interception is used to describe the uptake of soil nutrients at the root interface when soil volume is displaced by root volume (Barber 1995). However, Tinker and Nye (2000) consider the concept of interception to be somewhat arbitrary and argued that it can be included in the diffusion component. Although conditions in the rhizosphere are sometimes different from those in the bulk soil (Marschner 1995), the contribution of interception to nutrient uptake is negligible for most nutrients (Barber 1995). Therefore, only mass flow and diffusion are considered to be responsible for movement of nutrients to the root surface in mechanistic modeling. 
Table 1. List of symbols and definitions used in mechanistic nutrient uptake model equations.

\begin{tabular}{|c|c|}
\hline Symbol & Definition \\
\hline $\mathrm{b}$ & buffer power of nutrient \\
\hline $\mathrm{C}$ & nutrient concentration in soil \\
\hline $\mathrm{C}_{\mathrm{av}}$ & average nutrient concentration in soil solution \\
\hline $\mathrm{C}_{\mathrm{L}}$ & nutrient concentration in soil solution \\
\hline $\mathrm{C}_{\mathrm{L} 0}$ & nutrient concentration in soil solution at the root surface \\
\hline $\mathrm{C}_{\mathrm{Li}}$ & initial concentration of the nutrient in the soil solution \\
\hline $\mathrm{C}_{\min }$ & concentration in solution below which net influx ceases \\
\hline $\mathrm{C}_{\mathrm{s}}$ & nutrient concentration in soil solid phase \\
\hline $\mathrm{D}$ & diffusion coefficient of solute \\
\hline $\mathrm{D}_{\mathrm{e}}$ & effective diffusion coefficient for the nutrient in the soil \\
\hline $\mathrm{D}_{\mathrm{L}}$ & diffusion coefficient of solute in water \\
\hline $\mathrm{E}$ & nutrient efflux of plant roots \\
\hline $\mathrm{F}$ & flux of solute \\
\hline $\mathrm{F}_{\mathrm{D}}$ & flux of solute by diffusion \\
\hline$F_{M}$ & flux of solute by mass flow \\
\hline$f_{L}$ & impedance factor of soil liquid-phase \\
\hline$f_{s}$ & impedance factor of soil solid-phase \\
\hline I & net influx of solute per unit area of root surface \\
\hline $\mathrm{I}_{1}$ & net influx of solute per unit length of root \\
\hline$I_{\max }$ & maximum net influx at high nutrient concentrations \\
\hline $\mathrm{k}$ & rate of root growth \\
\hline $\mathrm{K}_{\mathrm{m}}$ & Michaelis-Menten constant \\
\hline $\mathrm{L}_{0}$ & initial root length \\
\hline $\mathrm{L}_{\mathrm{v}}$ & root length density \\
\hline $\mathrm{r}$ & radial distance in soil from the root surface \\
\hline $\mathrm{r}_{0}$ & mean root radius \\
\hline$r_{1}$ & half-distance between root axes \\
\hline $\mathrm{t}$ & time \\
\hline$\Delta \mathrm{U}$ & $\begin{array}{l}\text { the amount of nutrient uptake by root of unit length within a time } \\
\text { period }\end{array}$ \\
\hline $\mathrm{U}$ & the amount of nutrient uptake by root \\
\hline $\mathrm{U}_{\mathrm{p}}$ & $\begin{array}{l}\text { the amount of nutrient uptake by root system within a time period } \\
\text { predicted by PCATS }\end{array}$ \\
\hline $\mathrm{v}$ & mean water influx \\
\hline $\mathrm{v}_{0}$ & mean water influx at root surface \\
\hline $\mathrm{v}_{1}$ & water influx at the distance $\mathrm{r}_{1}$ \\
\hline $\mathrm{x}$ & distance \\
\hline$\Delta \mathrm{x}$ & the extension of nutrient depletion zone in soil \\
\hline$\alpha$ & root absorbing power \\
\hline$\theta$ & volumetric soil moisture \\
\hline$\rho$ & soil bulk density \\
\hline
\end{tabular}




\section{$\underline{\text { Mass flow }}$}

Mass flow is the convective transport of nutrients through the soil to the root surface by water flow as a result of transpiration (Barber 1995). The relative contribution of mass flow to nutrient uptake depends on the nutrient, plant species, plant age, and time of day (Marschner 1995). For example calcium and magnesium supplied to plants by mass flow is significant, but its contribution to potassium supply is negligible (Marschner 1995). The influx by mass flow $\left(\mathrm{F}_{\mathrm{M}}\right)$ can be calculated by

$$
F_{M}=v C_{L}
$$

where $\mathrm{v}$ is the mean water flux in soil driven by transpiration, and $\mathrm{C}_{\mathrm{L}}$ is the nutrient concentration in the soil solution (Barber 1995).

\section{Diffusion}

Diffusion is the movement of nutrients from areas of high concentration to those of low concentration (Barber 1995). It is the main mechanism for at least phosphorus and potassium movement in the soil to plant roots (Marschner 1995). A depletion zone is produced when the concentration of nutrient is lowered near the root surface due to root absorption (Jungk and Claassen 1997). Diffusive flux $F_{D}$ can be described by Fick's first law,

$$
F_{D}=-D \frac{d C}{d x}
$$

where $\mathrm{D}$ is the diffusion coefficient of the nutrient in soil, $\mathrm{C}$ is the nutrient concentration in soil solution, and $\mathrm{x}$ is the distance. Diffusion in soils includes solute diffusion in soil solution and the surface diffusion on the soil solid phase (Tinker and Nye 2000). Thus the diffusion coefficient is calculated by

$$
D=D_{L} f_{L} \theta d C_{L} / d C+D_{L} f_{S} \rho d S_{S} / d C
$$

where $D_{L}$ is the diffusion coefficient of the solute in free solution, $\theta$ is the soil moisture, $\rho$ is soil bulk density, $\mathrm{f}_{\mathrm{L}}$ and $\mathrm{f}_{\mathrm{s}}$ are liquid- and solid-phase impedance factors, respectively, and $\mathrm{S}_{\mathrm{s}}$ is the amount of solute adsorbed on a unit weight of solid (Tinker and Nye 2000). The first part of equation [3] represents solute diffusion in solution, while the second part represents the surface diffusion on the soil solid phase. Usually only diffusion in soil solution is considered in the mechanistic nutrient uptake models, and the equation for the diffusion coefficient is reduced to

$$
D=D_{L} f_{L} \theta d C_{L} / d C
$$


With the addition of the equation for buffer power $b$

$$
b=\frac{\mathrm{d} C}{\mathrm{~d} C_{L}}
$$

equation [4] is rewritten as:

$$
D_{e}=\frac{D_{L} f_{L} \theta}{b}
$$

where $D_{e}$ is called the effective diffusion coefficient. It is also assumed that the liquid-impedance factor $f_{L}$ is responsible for all the retarding effects from the solution and the solid phase during the process of diffusion (Tinker and Nye 2000) and mainly reflects the tortuosity, water density, and surface changes in the soil (Barber 1995).

Buffer power (b) reflects the relationship between nutrient concentration in the soil (C) and in the soil solution $\left(\mathrm{C}_{\mathrm{L}}\right)$, and can be derived from sorption isotherms. Different sorption equations have been proposed. For example, $C=m C_{L}^{n}+a$, if the Freundlich equation is adopted, where $\mathrm{a}, \mathrm{m}$, and $\mathrm{n}$ are regression constants. Therefore, $\mathrm{b}$ can be obtained from such isotherm equations. Because the isotherm is usually non-linear, $b$ is not constant when $C_{L}$ changes.

The extension of the depletion zone can be calculated by

$$
\Delta x=\sqrt{\pi D t}
$$

where $\Delta \mathrm{x}$ is the distance at which the decrease of concentration is $20 \%$ of the maximum decrease at the root surface, and $t$ is time (Syring and Claassen 1995).

\section{Simultaneous mass flow and diffusion}

Mass flow and diffusion occur simultaneously to supply nutrients to plant roots and cannot be treated as separate processes. Nye and Spiers (1964) presented a partial differential equation (equation 8) to describe simultaneous mass flow and diffusion, and this equation became the foundation of the most mechanistic nutrient uptake models.

\section{Plant Properties}

\section{Root morphology and growth}

The root system that provides the plant with water and nutrients is very complex and dynamic. The basic mechanistic nutrient uptake models simplify the system by describing it with a few parameters. Root radius $\left(\mathrm{r}_{0}\right)$ is used to describe the root morphology. Root hairs play an 
important role in some plants and the radius of the root hair is included if uptake by root hairs is considered. Initial root length $\left(\mathrm{L}_{0}\right)$ and root growth rate $(\mathrm{k})$ are used to describe root growth. Two destructive harvests are usually required to obtain these parameters. Two mathematical methods are available to describe root growth rate. The linear way is to calculate $\mathrm{k}$ by

$$
k=\frac{L_{2}-L_{1}}{t_{2}-t_{1}}
$$

where $t$ and $L$ represent the time and root length at individual harvests, 1 and 2 representing the first and second harvest. The exponential way is to calculate $\mathrm{k}$ by

$$
k=\frac{\ln L_{2}-\ln L_{1}}{t_{2}-t_{1}}
$$

Half distance between root axes $\left(r_{1}\right)$ is used to describe the influence of inter-root competition on nutrient uptake simulation. It is calculated by

$$
r_{1}=\sqrt{\frac{1}{\pi L_{v}}}
$$

where $L_{v}$ is the root length density (Barber 1995).

\section{Nutrient uptake kinetics}

\section{Nutrient uptake mechanisms}

The transport of nutrients across the cell membrane is the rate-limiting step when the nutrient supply is abundant (Williams and Yanai 1996). When nutrients arrive at the root surface, they are available for root absorption. The process can be divided into two types, passive and active uptake (Lodish et al. 2001). Passive uptake of nutrients refers to the transmembrane movement of nutrients without the consumption of energy (Lodish et al. 2001). It includes diffusion and facilitated diffusion along the concentration gradient between the inside and outside of the cell membrane (Lodish et al. 2001). Facilitated diffusion is the diffusion of ions with the help of ion channels or carrier proteins on the cell membrane (Lodish et al. 2001). For those nutrients whose concentration inside the cell is higher than outside, they will be transported across the membrane at the cost of energy, usually with the help of various membrane transporters (Lodish et al. 2001).

Marschner (1995) summarized the uptake isotherms and divided essential nutrients into three categories: (i) the uptake of potassium, phosphorus, nitrate, and sulfur usually depends on the 
external nutrient concentration before it becomes saturated; (ii) the uptake of sodium, calcium, and magnesium also depends on the external concentration, but to a less extent, and there is no obvious pattern for leveling off; and (iii) boron uptake is by diffusion, in direct proportion to the external concentration. Recent studies of boron uptake by crop plants suggest that the mechanism of boron uptake is more complex. It involves both active and passive mechanisms, depending on the boron concentration in the soil solution at the root surface (Dannel et al. 2000; Pfeffer et al. 2001).

\section{Modeling nutrient uptake kinetics}

As early as the 1960s, root absorbing power $(\alpha)$ was used to connect the nutrient concentration in soil solution and the influx of nutrient into cells using the equation of Nye and Spiers (1964):

$$
F=\alpha C_{L 0}
$$

where $\mathrm{C}_{\mathrm{L} 0}$ is the nutrient concentration in soil solution at the root surface. $\alpha$ was assumed to be constant before the influx reaches its maximum (Nye and Spiers 1964; Nye and Marriott 1969; Baldwin et al. 1973; Nye and Tinker 1977). That is, influx increases linearly as the nutrient concentration in soil solution increases until the concentration reaches a critical point, above which the influx will be constant. If net influx per unit length of root $\left(\mathrm{I}_{1}\right)$ is used, the equation (Baldwin et al. 1973; Nye and Tinker 1977) is transformed to

$$
I_{l}=2 \pi r_{0} \alpha C_{L 0}
$$

where $r_{0}$ is the root radius.

Reflecting advances in the understanding of cell biology, the mechanism of active uptake was incorporated into the models by Claassen and Barber (1976). Active uptake is described by the Michaelis-Menten equation:

$$
I=\frac{I_{\max }\left(C_{L 0}-C_{\min }\right)}{K_{m}+C_{L 0}-C_{\min }} \text { or } I=\frac{I_{\max } C_{L 0}}{K_{m}+C_{L 0}}-E
$$

where $I$ is the nutrient influx per unit area of root surface, $I_{\max }$ is the maximal influx at high $C_{L}$, $\mathrm{K}_{\mathrm{m}}$ is the Michaelis-Menten constant, $\mathrm{C}_{\min }$ is the solution concentration at which influx equals to efflux, and $\mathrm{E}$ is the efflux of ions from roots into solution.

The relationship between $\mathrm{C}_{\mathrm{L} 0}$ and I described by Michaelis-Menten equation indicates that the root absorbing power constantly changes as $\mathrm{C}_{\mathrm{L} 0}$ changes. To incorporate active uptake 
kinetics in their model, Smethurst and Comerford (1993b) used a variable root absorbing power (equation 15).

$$
\alpha=\frac{I_{\max }}{K_{m}+C_{L 0}-C_{\min }}
$$

\section{Modeling Approaches}

Over the past four decades different mechanistic nutrient uptake models have been developed to simulate nutrient uptake. Usually, these models consist of three basic components (Rengel 1993): (i) solute movement in the soil toward plant roots described by the continuity equation (equation 8); (ii) nutrient uptake kinetics described by the Michaelis-Menten equation (equation 14); (iii) nutrient uptake as a result of root growth and inter-root competition by introducing root growth and morphology parameters. Two categories of models have evolved, steady state and transient models (Tinker and Nye 2000). NST 3.0 is an example of a transient model with a numerical solution, while SSAND and PCATS are steady state models.

The basic principles of NUTRIENT UPTAKE and NST 3.0

Transient models utilizing numerical solutions are a well established approach to mechanistic nutrient uptake models (Tinker and Nye 2000). The Barber-Cushman model is a well-known and widely-used model in this category. NUTRIENT UPTAKE model and NST 1.0 are the personal computer version of the Barber-Cushman model (Oates and Barber 1987; Claassen et al. 1968). NST 3.0 is an improved version of NST 1.0. In this section, the principles of NUTRIENT UPTAKE model are presented, followed by a brief introduction to NST 3.0.

The Barber-Cushman model is largely based on the work by Nye and Marriot (1969). Nye and Marriot (1969) revised the continuity equation proposed by Nye and Spiers (1964) (see equation 8 ) to describe the flux of nutrient in the soil to the root surface with the nutrient concentration in soil solution $\left(\mathrm{C}_{\mathrm{L}}\right)$ :

$$
\frac{1}{r} \frac{\partial\left(r D \frac{\partial C_{L}}{\partial r}+\frac{v_{0} r_{0} C_{L}}{b}\right)}{\partial r}=\frac{\partial C_{L}}{\partial t}
$$

where $\mathrm{v}_{0}$ is the water flux at the root surface, $\mathrm{r}$ is the radial distance from the root, and $\mathrm{t}$ is time. Nye and Marriot (1969) defined boundary conditions and solved this equation numerically. 
Summarizing the work by Claassen and Barber (1976) and Cushman (1979a; 1979b), Barber and Cushman (1981) suggested new boundary conditions for the equation [16] to include interroot competition for nutrients:

(1) Inner boundary condition

$$
t>0, r=r_{0}, F=D b \frac{\partial C_{L}}{\partial r}+v_{0} C_{L}=\frac{\alpha C_{L}}{1+\alpha C_{L} / I_{\max }}-E
$$

where $\left(\frac{\alpha C_{L}}{1+\frac{\alpha C_{L}}{I \max }}-E\right)$ is a transformation of the equation [14].

(2) Outer boundary condition:

If there is no inter-root competition,

$$
t>0, r=r_{1}, C_{L}=\text { constant }
$$

If there is inter-root competition,

$$
t>0, r=r_{1}, F=D b \frac{\partial C_{L}}{\partial r}+v_{1} C_{L}=0
$$

where $\mathrm{v}_{1}$ is the water influx at a distance of $\mathrm{r}_{1}$.

The new boundary conditions incorporated inter-root competition as well as MichaelisMenten kinetics. When solved numerically, the enhanced mechanistic model evolved into Barber-Cushman model. In 1983 Itoh and Barber developed a submodel to the Barber-Cushman model to include nutrient uptake by root hairs.

In 1986 Claassen et al. published NST 1.0 model. In 1987 Oates and Barber published NUTRIENT UPTAKE model. Both were based on the Barber-Cushman model. Later Claassen and his colleagues developed NST 2.0 and NST 3.0, which were not published in a journal (Claassen, N. Personal communication. 2009, 31 July). NST 3.0 incorporates the Freundlich isotherm into the model so that the buffer power (b) changes as the nutrient concentration in soil solution changes (Steingrobe et al. 2000).

The basic principles of COMP8, SSAND, and PCATS

Steady state models are the other standard method in mechanistic nutrient uptake modeling (Tinker and Nye 2000). Baldwin et al. (1973) and Nye and Tinker (1977) proposed the key equations in 1970s. Based on their work, Smethurst and Comerford (1993b) developed a computer model, COMP8 (Competition model version 8), which was able to calculate nutrient uptake between two competing and contrasting root systems. SSAND was a revision and 
expansion of COMP8 by Comerford et al. (2006). Its main improvements lie in the functions of predicting nutrient uptake as influenced by mycorrhizae and simulation of fertilization effects (Comerford et al. 2006). Based on COMP8 and an earlier version of SSAND, another steady state model, PCATS was developed to simulate nutrient uptake by a single species by Smethurst et al. (2004). In this section, the principle of steady state models is briefly described; and the features of COMP8, SSAND and PCATS are introduced.

Based on the continuity equation by Nye and Spiers (1964) (see equation 8), Baldwin et al. (1973) and Nye and Tinker (1977) proposed the key equations of the concentration profile around the root as well as the average concentration for use in a steady state model.

$$
\frac{C_{L r}}{C_{L 0}}=\frac{\alpha}{v_{0}}+\left[1-\frac{\alpha}{v_{0}}\right]\left(\frac{r}{a}\right)^{-\left(\frac{r_{0} v_{0}}{b D}\right)}
$$

where $\mathrm{C}_{\mathrm{Lr}}$ is the nutrient concentration in soil solution at the distance $\mathrm{r}$ from the root.

By representing the average concentration across the depletion zone with $\mathrm{C}_{\mathrm{av}}$, the relationship between $\mathrm{C}_{\mathrm{av}}$ and $\mathrm{C}_{\mathrm{L} 0}$ can be obtained by

$$
\frac{C_{a v}}{C_{L 0}}=\frac{\alpha}{v_{0}}+\left(1-\frac{\alpha}{v_{0}}\right)\left(\frac{2}{2-\frac{r_{0} v_{0}}{b D}}\right) \frac{\left(\frac{r_{1}}{r_{0}}\right)^{\left(2-\frac{r_{0} v_{0}}{b D}\right)}-1}{\left(\frac{r_{1}}{r_{0}}\right)^{2}-1}
$$

Because the amount of nutrient uptake $\Delta U$ during the time period $\Delta t$ is given by

$$
\Delta U=2 \pi r_{0} L_{v} \alpha C_{L 0} \Delta t
$$

$\Delta U$ can be calculate by equation [23] and [24]. That is

$$
\Delta U=2 \pi r_{0} L_{v} \alpha \Delta t \frac{C_{a v} v_{0}}{\alpha+\left(v_{0}-\alpha\right)\left(\frac{2}{2-\frac{r_{0} v_{0}}{b D}}\right) \frac{\left(\frac{r_{1}}{r_{0}}\right)^{\left(2-\frac{r_{0} v_{0}}{b D}\right)}-1}{\left(\frac{r_{1}}{r_{0}}\right)^{2}-1}}
$$

At time interval $\Delta t_{1}, \mathrm{C}_{\mathrm{av} 1}=\mathrm{C}_{\mathrm{Li}}$. Therefore the new $\mathrm{C}_{\mathrm{av} 2}$ can be calculated from the uptake at time interval $\Delta t_{2}$, and $\mathrm{C}_{\mathrm{La} 2}$ can be calculated from $\mathrm{C}_{\mathrm{av} 2}$. This approach allows any time period to be represented (Tinker and Nye 2000). Finally, the total amount of nutrient uptake can be obtained by summing $\Delta U$ at each time interval. 
Smethurst and Comerford (1993b) developed COMP8 based on the above equation and another equation dealing with the competition between two root systems, with the improvements that allow for (i)" a depletion zone that increases with time until it reaches the no-transfer boundary, (ii) an adjustment in concentration to reflect newly encountered solutes in the depletion zone, (iii) a variable root absorbing power $\alpha$ (see equation 15) to describe MichaelisMenten uptake kinetics, and (iv) a routine to account for the competition between two root systems". Two verification studies with slash pine and weeds were also conducted in the same year (Smethurst and Comerford 1993a; Smethurst et al. 1993). However, this model has had little use since 1993 because it was inadequate under some conditions possibly due to the inability of the model to describe some components of the soil-root system such as root length development, changing moisture contents, and the nutrient input from mineralization (Smethurst and Comerford 1993b).

Based on COMP8, SSAND included several new functions allowing simulation of nutrient uptake by roots under a variety of conditions such as mycorrhizal roots, fertilization, changing soil water content, nutrients from different soil horizons, and dynamic mineralization rates (Comerford et al. 2006). It includes sub-routines to calculate the nutrient demand for a target plant growth, so that it can provide a recommendation on fertilization by comparing the predicted uptake and demand.

Similar to SSAND, PCATS is able to simulate nutrient uptake by mycorrhizae as well as uptake influenced by fertilization (Smethurst et al. 2004). However, it can only predict nutrient uptake by one species. It also uses an analytical solution similar to COMP8 and SSAND, but further simplifies the calculation by running on a fixed daily time-step (Smethurst et al. 2004). Assumptions for the mechanistic models

A number of specific assumptions underlie the models.

- The soil is homogeneous and isotropic (Rengel 1993).

- Nutrients move to the root by a combination of mass flow and diffusion (Barber 1995).

- Roots are smooth cylinders and the nutrient absorbing power is the same over all the cylinders (Barber 1995). 
- Mycorrhizae, root hairs, root exudates, or microbial activity on the root surface do not influence nutrient flux (Barber 1995).

- Nutrient uptake can be described by Michaelis-Menten kinetics and the kinetics parameters do not change over time (Barber 1995).

- Influx is independent of the rate of water absorption (Barber 1995)

- For NST 3.0, the soil moisture is essentially constant (Barber 1995). The roots are distributed evenly in the whole soil volume, and no allowance is given for a changing distance among roots as roots grow (Claassen and Steingrobe 1999); A root segment can exploit only a limited volume of soil, and the root is at the center of this cylinder (Claassen and Steingrobe 1999).

- For SSAND and PCATS, Roots are assumed to be parallel and distributed regularly throughout the soil volume (Baldwin 1973).

\section{Comparison of the two major categories of mechanistic models}

Usually transient state models with a numerical solution are considered to be more accurate than steady state models (Smethurst and Comerford 1993b; Yanai 1994). Numerical methods are those that "iteratively solve a system of simultaneous equations developed from approximations of the differential equation for solute transport" (Smethurst and Comerford 1993b). "The steady state approach assumes that the concentration profile around the root can be considered to be in a steady state" (Yanai 1994), which is usually attained after long periods of time (Nye and Spiers 1964). Since natural phenomena are transient, the results obtained using this approach may not be as accurate as the transient state model.

The major advantage of a steady state model over a transient state model lies in "the independence of the mathematical solution to previous condition" during calculation (Yanai 1994) so that steady state models are able to respond to real-time changes in parameters. Transient state models using a numerical solution are also called "deterministic" models (Claassen and Steingrobe 1999) because the simulation does not accept time-varying input (Yanai 1994). For example, soil moisture is not allowed to change during the calculation, though it is unrealistic to think that soil moisture would remain constant in the field. 


\section{Current study on NST 3.0, SSAND, and PCATS}

As a transient model utilizing a numerical solution, NST 3.0 has been used widely to predict uptake of nutrients by various crop species (Sadana and Claassen 2000; Satnam and Sadana 2002; Samal et al. 2003; Sadana et al. 2005; Pypers et al. 2006). However, no studies on woody species utilizing this model have been conducted.

Smethurst and Comerford (1993b) verified the ability of COMP8 to predict a one-species scenario by comparing its responses with those of the NUTRIENT UTPAKE model. They also published the verification of COMP8 by predicting potassium and phosphorus uptake by slash pine in competition with weeds using both pot and field studies (Smethurst and Comerford 1993a; Smethurst et al. 1993). In the pot study, the model provided a good representation of potassium and phosphorus uptake by pines and weeds under high nutrient concentration treatments, but performed poorly under low nutrient concentration treatments (Smethurst and Comerford 1993a). In the field study, the model predicted the phosphorus and potassium uptake by pines adequately, but significantly over predicted uptake of both nutrients by weeds (Smethurst et al. 1993). Ibrikci et al. (1994) studied phosphorus uptake by Bahiagrass with COMP8. The prediction matched the observation for 18-day-old plants growing in Ap, E, and Bh horizons, but a low level of agreement was found at 90 days for plants growing in Ap and $\mathrm{E}$ horizon soils, both of which were known to be of low phosphorus supply (Ibrikci et al. 1994). Four years later, Ibrikci and his colleagues (1998) found that the nitrogen uptake predicted for COMP8 was $38 \%$ to $44 \%$ lower than that observed by field-grown corn (Ibrikci et al. 1998). The potential error of adopting an $\mathrm{I}_{\max }$ value from the literature and COMP8's inability to include contributions from root hairs and nitrogen mineralization were suggested by Ibrikci et al. (1994) as the reasons for their underestimates.

SSAND was published in 2000 (Li and Comerford 2000); the authors verified it by predicting phosphorus uptake by 1-yr loblolly pine growing in southeastern Georgia and Florida (Comerford et al. 2006). Borges-Gómez et al. (2008) used SSAND to predict potassium requirement by habanero pepper in Yucatán, Mexico. But they used SSAND as a tool for management and did not compare the model predictions to any observations of uptake. Singh (2008) investigated the uptake of nitrogen, phosphorus, and potassium by hybrid poplar and weeds in both the lab and field using SSAND. The disagreement between the simulated and 
observed uptake was significant except for the simulation of nitrogen uptake by hybrid poplar in the control field site (Singh 2008). Only one paper is available for the model PCATS. The authors verified the model by comparing the PCATS estimates of uptake to these provided by NUTRIENT UPTAKE model (Smethurst et al. 2004).

To summarize, the differences between NST 3.0, SSAND, and PCATS are not well understood in terms of predictive accuracy and model behavior. The different solution methods used in the models may lead to different simulations. Reported research to date related to the use of SSAND and PCATS is limited. Agreement between the predictions of their predecessor model, COMP8, and observations was not good under some situations such as low nutrient supply scenarios (Smethurst and Comerford 1993a). Although NST 3.0 performed well with crop species, no tests have been done with woody species. Because no study has been conducted to compare the efficacy of the three models, it would be beneficial to evaluate the three models by comparing the predictions with observations using multiple datasets representing various situations taken from the literature.

\section{Sensitivity Analysis of Mechanistic Nutrient Uptake Models}

The traditional sensitivity analysis can also be called a one dimensional sensitivity analysis. This approach was first used to by Silberbush and Barber in 1983 to show the influence of different parameters on model simulations. It was accomplished by changing a single model input parameter while keeping the others constant (Silberbush and Barber 1983). By plotting the change ratio of the parameters compared to their original values on the horizontal axis, and the predicted uptake to the original prediction on the vertical axis, it is possible to evaluate the importance of each parameter by the slope of the line on the graph. This procedure has been largely followed in all subsequent analysis. Although Claassen and Steingrobe (1999) proposed to treat initial soil solution concentration $\left(\mathrm{C}_{\mathrm{Li}}\right)$ and buffer power $(\mathrm{b})$ together in the analysis because the two parameters are related to each other, the principle is the same.

Yanai proposed the idea of multiple dimensional sensitivity analysis in 1994 and did several two dimensional sensitivity analyses. Two years later Williams and Yanai conducted a multiple dimensional sensitivity analysis using a simplified steady state model to simulate nutrient uptake by a unit length of root (Williams and Yanai 1996). Because the model they used did not take root growth and inter-root competition into account, it contained 7 parameters, while a typical 
mechanistic nutrient uptake model has 11 parameters. By changing each parameter at 4 levels, 16,384 parameter datasets were created. Using ANOVA, they found up to four-way interactions among the parameters with $\mathrm{C}_{\mathrm{av}}, \mathrm{I}_{\max }, \mathrm{D}_{\mathrm{e}}$, and $\mathrm{r}_{0}$ exerting the most significant influences on the simulations (Williams and Yanai 1996). They then represented each of 5 parameters (these 4 parameters plus water influx into roots) at 5 levels and plotted the response surface using graphs (Williams and Yanai 1996). The response surfaces developed using this method indicated clear relationships between the selected parameters. For example, the most influential parameters depend on the concentration of nutrients supplied by soil processes (Williams and Yanai 1996). When the concentration is low, the soil parameters dominate the uptake process. When the concentration is high, the parameters representing the ability of the plant root to take up nutrients, such as $\mathrm{I}_{\max }$ and $\mathrm{r}_{0}$, will determine how much nutrient is taken up (Williams and Yanai 1996).

Therefore, the multiple dimensional sensitivity analysis is a powerful tool in helping us understand model behavior under various situations. However, since the simplified mechanistic model used by Williams and Yanai (1996) did not include inter-root competition and root growth, using this method to analyze NST 3.0, SSAND, and PCATS with the key parameters $C_{a v}, I_{\max }, D_{e}, r_{0}$, plus the parameters of root growth and inter-root competition would provide a more complete evaluation of the model behaviors and explore the potential differences between the three models more thoroughly.

\section{Nutrient Uptake Modeling of Woody Species}

Gillespie and Pope (1990) used the Barber-Cushman model combined with a model on rhizosphere acidification to study phosphorus uptake by black locust. It is the first study to employ a minimalistic mechanistic nutrient uptake model to study a woody species. Gillespie and Pope (1990) found that the predictions matched the observations well if the influence of rhizosphere acidification was considered. In the same year, Van Rees et al. (1990) reported a study on potassium uptake by slash pine with both the Barber-Cushman and the Baldwin-NyeTinker models. The Baldwin-Nye-Tinker model (BNTM) was developed by Baldwin et al. in 1973 and became the foundation for COMP8 in 1993. Van Rees et al. (1990) found that the prediction by BNTM was 5\% higher than that by the Barber-Cushman model and that both models only worked well under situations treated with fertilizers. 
In collaboration with S. A. Barber, Kelly and Barber (1991) reported the magnesium uptake kinetics parameters of loblolly pine as well as the influence of seedling age on these parameters. In the following year, Kelly et al. (1992) verified the use of the Barber-Cushman model on phosphorus and potassium uptake by loblolly pine seedlings, but the simulated uptake of magnesium was substantially underestimated. From the mid 1990s to the early 2000s, Kelly and his coworkers used NUTRIENT UPTAKE model to study the uptake of several macro-nutrients by various tree species under different growing treatments (Kelly et al. 1995; Kelly et al. 2000; Kelly and Kelly 2001; Kelly et al. 2001; Adam et al. 2003; Kelly and Ericsson 2003). The research largely focused on the influence of environmental factors and plant growth on parameter values, such as the seasonal dynamics of soil supply capacities (Kelly et al. 1995) and the uneven growth of roots during a growing season (Kelly et al. 2001). Some limitations of NUTRIENT UPTAKE model were also pointed out, such as the fixed root growth rate (Kelly et al. 2001) and the inability to include the contributions of decomposition and mineralization during the simulation (Kelly and Ericsson 2003). Adam et al. (2003) also used these parameters and the established methodology as tools to study the influence of temperature on uptake kinetics (Adam et al. 2003).

Unlike the Barber-Cushman model, the steady state model has been constantly revised since 1990s, and most of the studies were conducted with woody species. Because COMP8, Yanai's model in 1994, SSAND, and PCATS are important achievements in the development of the steady state model, and they are discussed in the section discussing the current studies of SSAND and PCATS, these studies are not repeated here. Yanai (2003) used the steady state mechanistic model she proposed in 1994 to calculate the nutrient concentration differences between rhizosphere and bulk soil in a Norway spruce stand. She found that in contrast to the model calculation, the observed nutrient concentrations in the rhizosphere were generally higher than those in bulk soil (Yanai et al. 2003).

Representative ranges for parameters needed conduct a multiple dimensional sensitivity analysis are presented in Tables 2, 3, and 4 and list values from the literature for nutrient uptake kinetics, soil supply, and root growth parameter. 
Table 2. Nutrient uptake kinetics parameters for a variety of woody species taken from the literature.

\begin{tabular}{|c|c|c|c|c|c|c|}
\hline Nutrient & Species & Common name & $\begin{array}{c}\mathrm{I}_{\max } \\
\mu \mathrm{mol} \mathrm{cm} \mathrm{cm}^{-1}\end{array}$ & $\begin{array}{c}\mathrm{K}_{\mathrm{m}} \\
\mu \mathrm{mol} \mathrm{cm}\end{array}$ & $\begin{array}{c}\mathrm{C}_{\min } \\
\mu \mathrm{mol} \mathrm{cm}\end{array}$ & Source \\
\hline \multirow[t]{3}{*}{$\mathrm{NH}_{4}-\mathrm{N}$} & Populus sp. & hybrid poplar & 0.000004 & 0.049 & 0.001 & (Singh 2008) \\
\hline & Picea glauca & white spruce & 0.0000207 & 0.20568 & & (Hangs et al. 2003) \\
\hline & Populus tremuloides & aspen & 0.00001254 & 0.21712 & & (Hangs et al. 2003) \\
\hline \multirow{6}{*}{$\mathrm{NO}_{3}-\mathrm{N}$} & Populus sp. & hybrid poplar & $0.0000034-0.0000285$ & $0.093-0.712$ & 0.001 & (Kelly and Ericsson 2003) \\
\hline & Acer rubrum & red maple & $0.0000157-0.00005908$ & $0.204-0.523$ & 0.001 & (Kelly et al. 2000) \\
\hline & Acer rubrum & red maple & $0.0000195-0.0000318$ & $0.000088-0.00019$ & $0.000018-0.000066$ & (Adam et al. 2003) \\
\hline & Acer rubum & red maple & 0.0000309 & 0.32 & 0.001 & (Kelly et al. 2001) \\
\hline & Picea glauca & white spruce & 0.0000045 & 0.34451 & & (Hangs et al. 2003) \\
\hline & Populus tremuloides & Aspen & 0.00000581 & 0.3365 & & (Hangs et al. 2003) \\
\hline \multirow[t]{7}{*}{$\mathrm{K}$} & Populus sp. & hybrid poplar & 0.0000176 & 0.0269 & 0.003 & (Kelly and Ericsson 2003) \\
\hline & Populus sp. & hybrid poplar & 0.00000266 & 0.034 & 0.001 & (Singh 2008) \\
\hline & Acer rubrum & red maple & 0.0000038 & 10.46 & 0.003 & (Kelly and Kelly 2001) \\
\hline & Pinus elliottii var. elliottii & slash pine & 0.00000361 & 0.029 & 0.001 & (Van Rees et al. 1990) \\
\hline & Pinus elliottii var. elliottii & slash pine & 0.00000361 & 0.029 & 0.001 & (Van Rees and Comerford 1990) \\
\hline & Pinus taeda & loblolly pine & 0.0000014 & 0.03 & 0.001 & (Kelly et al. 1992) \\
\hline & Pinus taeda & loblolly pine & 0.00000365 & 0.0237 & 0.0002 & (Kelly et al. 1995) \\
\hline \multirow[t]{7}{*}{$\mathrm{P}$} & Populus sp. & hybrid poplar & 0.00000151 & 0.00087 & 0.001 & (Kelly and Ericsson 2003) \\
\hline & Populus sp. & hybrid poplar & 0.00000113 & 0.038 & 0.001 & (Singh 2008) \\
\hline & Acer rubrum & red maple & 0.00000549 & 15.02 & 0.001 & (Kelly and Kelly 2001) \\
\hline & Pinus elliottii var. elliottii & slash pine & 0.000000643 & 0.00545 & 0.0002 & (Smethurst and Comerford 1993a) \\
\hline & Pinus taeda & loblolly pine & 0.000000268 & 0.016 & 0.0006 & (Kelly et al. 1992) \\
\hline & Pinus taeda & loblolly pine & 0.00000064 & 0.00545 & 0 & (Comerford et al. 2006) \\
\hline & Robinia pseudoacacia & black locust & 0.0000017 & 0.0018 & 0.0007 & (Gillespie and Pope 1990) \\
\hline \multirow[t]{4}{*}{$\mathrm{Mg}$} & Pinus taeda & loblolly pine & 0.000000112 & 0.00858 & 0.001 & (Kelly and Barber 1991) \\
\hline & Pinus taeda & loblolly pine & 0.000000079 & 0.00869 & 0.001 & (Kelly and Barber 1991) \\
\hline & Pinus taeda & loblolly pine & 0.000000129 & 0.00983 & 0.001 & (Kelly and Barber 1991) \\
\hline & Pinus taeda & loblolly pine & 0.000000129 & 0.00983 & 0.001 & (Kelly et al. 1992) \\
\hline
\end{tabular}


Table 3. Soil supply parameters from studies of a variety of woody species.

\begin{tabular}{|c|c|c|c|c|c|}
\hline Nutrient & $\begin{array}{c}\mathrm{C}_{\mathrm{Li}} \\
\mu \mathrm{mol} \mathrm{\textrm {ml } ^ { - 1 }}\end{array}$ & $\mathrm{b}$ & $\begin{array}{c}D_{e} \\
\mathrm{~cm}^{2} \mathrm{~s}^{-1} \\
\end{array}$ & Plant name & Source \\
\hline \multirow[t]{3}{*}{$\mathrm{NH}_{4}-\mathrm{N}$} & $0.0037-0.714$ & & & hybrid poplar & (Singh 2008) \\
\hline & $0.001-0.075$ & $4.9-209.3$ & $0.000000015-0.00000131$ & multiple species & (Kelly and Mays 1999) \\
\hline & $0.052-0.215$ & & $0.0000064-0.000015$ & Norway spruce & (Yanai et al. 2003) \\
\hline \multirow{4}{*}{$\mathrm{NO}_{3}-\mathrm{N}$} & $0.0761-2.31$ & $1.14-1.98$ & $0.000000684-0.000113$ & hybrid poplar & (Kelly and Ericsson 2003) \\
\hline & $0.047-10.714$ & & & hybrid poplar & (Singh 2008) \\
\hline & $0.002-2.33$ & $0.04-69.09$ & $0.000000191-0.0002$ & multiple species & (Kelly and Mays 1999) \\
\hline & 0.51 & 1.35 & 0.0000632 & red maple & (Kelly et al. 2001) \\
\hline \multirow[t]{13}{*}{$\mathrm{K}$} & $0.124-0.132$ & & & cottonwood & (Wang et al. 2004) \\
\hline & $0.0963-0.519$ & $1.4-5.095$ & $0.000000263-0.000000994$ & hybrid poplar & (Kelly and Ericsson 2003) \\
\hline & $1.432-3.529$ & & & hybrid poplar & (Singh 2008) \\
\hline & 0.27 & 10.55 & 0.00000329 & loblolly pine & (Kelly et al. 1992) \\
\hline & $0.99-8.54$ & $0.16-1.19$ & $0.000000664-0.00000635$ & loblolly pine & (Kelly et al. 1995) \\
\hline & $0.018-0.561$ & & & multiple species & (Kelly and Mays 1999) \\
\hline & $0.028-0.142$ & & $0.0000048-0.000017$ & Norway spruce & (Yanai et al. 2003) \\
\hline & 0.112 & 20 & 0.000000358 & red maple & (Kelly and Kelly 2001) \\
\hline & 0.13 & 7.02 & 0.00000171 & red maple & (Kelly et al. 2001) \\
\hline & $0.035-0.06$ & $3.00-3.44$ & $0.000000291-0.000000628$ & slash pine & (Van Rees et al. 1990) \\
\hline & $0.093-0.203$ & $3.64-6.26$ & $0.00000002-0.000000104$ & slash pine & (Van Rees and Comerford 1990) \\
\hline & $0.0382-0.338$ & $0.55-2.13$ & 0.00000019-0.00000128 & slash pine & (Smethurst and Comerford 1993a) \\
\hline & $0-0.36$ & $0.7-4.3$ & & slash pine & (Smethurst et al. 1993) \\
\hline \multirow[t]{6}{*}{$\mathrm{P}$} & $0.00161-0.00484$ & & & black locust & (Gillespie and Pope 1990) \\
\hline & $0.0287-0.0339$ & & & cottonwood & (Wang et al. 2004) \\
\hline & $0.0021-0.0388$ & $15.41-180.5$ & $0.000000003-0.000000041$ & hybrid poplar & (Kelly and Ericsson 2003) \\
\hline & 0.016 & & & hybrid poplar & (Singh 2008) \\
\hline & 0.19 & 5.84 & 0.000000817 & loblolly pine & (Kelly et al. 1992) \\
\hline & 0.0032 & & & loblolly pine & (Comerford et al. 2006) \\
\hline
\end{tabular}


Table 3. (Continued)

\begin{tabular}{|c|c|c|c|c|c|}
\hline Nutrient & $\begin{array}{c}\mathrm{C}_{\mathrm{Li}} \\
\mu \mathrm{mol} \mathrm{\textrm {ml } ^ { - 1 }} \\
\end{array}$ & $\mathrm{b}$ & $\begin{array}{c}D_{e} \\
\mathrm{~cm}^{2} \mathrm{~s}^{-1} \\
\end{array}$ & Plant name & Source \\
\hline \multirow[t]{5}{*}{$\mathrm{P}$} & $0.001-0.01$ & $84.5-1451.5$ & $0.0000000091-0.000000029$ & multiple species & (Kelly and Mays 1999) \\
\hline & 0.001 & 199 & 0.0000000203 & red maple & (Kelly and Kelly 2001) \\
\hline & 0.001 & 166.8 & 0.0000000143 & red maple & (Kelly et al. 2001) \\
\hline & $0.0226-1.21$ & $0.23-0.85$ & $0.00000019-0.0000013$ & slash pine & (Smethurst and Comerford 1993a) \\
\hline & $0-0.29$ & $0.7-1520$ & & slash pine & (Smethurst et al. 1993) \\
\hline \multirow[t]{3}{*}{$\mathrm{Ca}$} & $0.644-0.706$ & & & cottonwood & (Wang et al. 2004) \\
\hline & $0.019-0.599$ & & & multiple species & (Kelly and Mays 1999) \\
\hline & 0.004-0.009 & & 0.000019-0.000067 & Norway spruce & (Yanai et al. 2003) \\
\hline \multirow[t]{4}{*}{$\mathrm{Mg}$} & $0.560-0.609$ & & & cottonwood & (Wang et al. 2004) \\
\hline & 1.35 & 1.32 & 0.000000145 & loblolly pine & (Kelly et al. 1992) \\
\hline & $0.012-0.37$ & & & multiple species & (Kelly and Mays 1999) \\
\hline & $0.018-0.047$ & & $0.0000017-0.000006$ & Norway spruce & (Yanai et al. 2003) \\
\hline S & $0.028-0.051$ & & $0.0000026-0.000009$ & Norway spruce & (Yanai et al. 2003) \\
\hline
\end{tabular}


Table 4. Root growth parameters from a variety of woody species and the mean water flux at the root surface taken from the literature.

\begin{tabular}{|c|c|c|c|c|c|c|c|}
\hline Plant name & $\begin{array}{l}\mathrm{L}_{0} \\
\mathrm{~cm} \\
\end{array}$ & $\begin{array}{c}\mathrm{L}_{\mathrm{v}} \\
\mathrm{cm} \mathrm{cm}^{-3} \\
\end{array}$ & $\begin{array}{r}\mathrm{r}_{0} \\
\mathrm{~cm} \\
\end{array}$ & $\begin{array}{r}\mathrm{r}_{1} \\
\mathrm{~cm} \\
\end{array}$ & $\begin{array}{c}\mathrm{k} \\
\mathrm{cm} \mathrm{s}^{-1} \\
\end{array}$ & $\begin{array}{c}\mathrm{v}_{0} \\
\mathrm{~cm} \mathrm{~s}^{-1} \\
\end{array}$ & Source \\
\hline hybrid poplar & 1094 & & 0.02 & $0.573-0.664$ & $\begin{array}{l}0.000347- \\
0.00113\end{array}$ & 0.000000746 & (Kelly and Ericsson 2003) \\
\hline hybrid poplar & & $0.001-11.88$ & $0.01-0.03$ & & & 0.00000195 & (Singh 2008) \\
\hline box elder & & & 0.0675 & & & & (Comas et al. 2002) \\
\hline red maple & & & $0.035-0.0397$ & & & & (Adam et al. 2003) \\
\hline red maple & $3842-16179$ & & $0.028-0.042$ & & & & (Kelly et al. 2000) \\
\hline red maple & 1696 & & 0.044 & 0.99 & 0.000475 & 0.00000517 & (Kelly et al. 2001) \\
\hline sugar maple & & & 0.0685 & & & & (Comas et al. 2002) \\
\hline white spruce & & & 0.041 & & & & (Hangs et al. 2003) \\
\hline Norway spruce & & & 0.05 & $0.36-0.55$ & & $0.0000016-0.0000021$ & (Yanai et al. 2003) \\
\hline jack pine & & & 0.039 & & & & (Hangs et al. 2003) \\
\hline Eastern hemlock & & & 0.0783 & & & & (Comas et al. 2002) \\
\hline slash pine & 16.6-31.6 & & $0.036-0.06$ & $1.39-3.15$ & $\begin{array}{l}0.000012- \\
0.000184\end{array}$ & 0.00000379 & (Van Rees et al. 1990) \\
\hline slash pine & & $0.1-0.3$ & $0.0234-0.0932$ & & & 0.0000032 & $\begin{array}{l}\text { (Smethurst and Comerford } \\
\text { 1993a) }\end{array}$ \\
\hline slash pine & $11.9-41.3$ & & $0.027-0.046$ & $0.62-2.59$ & $\begin{array}{l}0.000064- \\
0.000455\end{array}$ & $\begin{array}{l}0.00000223- \\
0.00001035\end{array}$ & $\begin{array}{l}\text { (Van Rees and Comerford } \\
1990 \text { ) }\end{array}$ \\
\hline loblolly pine & $10-517.3$ & & $0.043-0.052$ & $2.47-6.02$ & $0.00004-0.00013$ & 0.000000566 & (Kelly et al. 1995) \\
\hline loblolly pine & 285 & & 0.035 & 2 & 0.000162 & 0.000000566 & (Kelly et al. 1992) \\
\hline loblolly pine & & 0.4 & 0.04 & & & 0.000002 & (Comerford et al. 2006) \\
\hline Virginia pine & & & 0.0741 & & & & (Comas et al. 2002) \\
\hline cottonwood & 301.1 & & & & & & (Wang et al. 2004) \\
\hline aspen & & & 0.043 & & & & (Hangs et al. 2003) \\
\hline white oak & & & 0.0504 & & & & (Comas et al. 2002) \\
\hline red oak & & & 0.0605 & & & & (Comas et al. 2002) \\
\hline black locust & & & & 0.941 & & 0.000000001 & (Gillespie and Pope 1990) \\
\hline
\end{tabular}




\section{Literature Cited}

Adam, M. L., J. M. Kelly, W. R. Graves and P. M. Dixon. 2003. Net nitrate uptake by red maple is a function of root-zone temperature. Journal of Plant Nutrition 26: 203-222.

Baldwin, J. P., P. H. Nye and P. B. Tinker. 1973. Uptake of solutes by multiple root systems from soil III - a model for calculating the solute uptake by a randomly dispersed root system developing in a finite volume of soil. Plant and Soil 38: 621635.

Barber, S. A. 1995. Soil nutrient bioavailability: a mechanistic approach. 2nd edition. John Wiley \& Sons, Inc., New York.

Barber, S. A. and J. H. Cushman 1981. Nitrogen uptake model for agronomic crops. p. 382-409 In I. K. Iskandar (ed.). Modeling waste water renovation-land treatment: Wiley-Interscience, New York.

Borges-Gómez, L., T. González-Estrada and M. Soria-Fregoso. 2008. Prediction of potassium requirements for Capsicum chinense Jacq. production in southeast Mexico. Tropical and Subtropical Agroecosystems 8: 69-80.

Bouldin, D. R. 1961. Mathematical description of diffusion processes in the soil-plant system. Soil Science Society of America Proceedings 25: 476-480.

Claassen, N. and S. A. Barber. 1976. Simulation model for nutrient uptake from soil by a growing plant root system. Agronomy Journal 68: 961-964.

Claassen, N. and B. Steingrobe 1999. Mechanistic simulation models for a better understanding of nutrient uptake from soil. p. 327-367 In Z. Rengel (ed.). Mineral nutrition of crops: fundamental mechanisms and implications: Food Products Press, New York.

Claassen, N., K. M. Syring and A. Jungk. 1986. Verification of a mathematical-model by simulating potassium uptake from soil. Plant and Soil 95: 209-220.

Comas, L. H., T. J. Bouma and D. M. Eissenstat. 2002. Linking root traits to potential growth rate in six temperate tree species. Oecologia 132: 34-43.

Comerford, N. B., W. P. Cropper, Jr., L. Hua, P. J. Smethurst, K. C. J. Van Rees, E. J. Jokela and F. Adams. 2006. Soil Supply and Nutrient Demand (SSAND): a general nutrient uptake model and an example of its application to forest management. Canadian Journal of Soil Science 86: 655-673.

Cushman, J. H. 1979a. An analytical solution to solute transport near root surfaces for low initial concentration: I. Equations' development. Soil Science Society of America Journal 43: 1087-1090. 
Cushman, J. H. 1979b. An analytical solution to solute transport near root surfaces for low initial concentration: II. Applications. Soil Science Society of America Journal 43: 1090-1095.

Dannel, F., H. Pfeffer and V. Römheld. 2000. Characterization of root boron pools, boron uptake and boron translocation in sunflower using the stable isotopes ${ }^{10} \mathrm{~B}$ and ${ }^{11} \mathrm{~B}$. Australian Journal of Plant Physiology 27: 387-405.

Gillespie, A. R. and P. E. Pope. 1990. Rhizosphere acidification increases phosphorus recovery of black locust: II. Model predictions and measured recovery. Soil Science Society of America Journal 54: 538-541.

Hangs, R. D., J. D. Knight and K. C. J. Van Rees. 2003. Nitrogen uptake characteristics for roots of conifer seedlings and common boreal forest competitor species. Canadian Journal of Forest Research 33: 156-163.

Ibrikci, H., N. B. Comerford, E. A. Hanlon and J. E. Rechcigl. 1994. Phosphorus uptake by bahiagrass from Spodosols: modeling of uptake from different horizons. Soil Science Society of America Journal 58: 139-143.

Ibrikci, H., A. C. Ulger, B. Cakir, G. Buyuk and N. Guzel. 1998. Modeling approach to nitrogen uptake by field-grown corn. Journal of Plant Nutrition 21: 1943-1954.

Itoh, S. and S. A. Barber. 1983. A numerical solution of whole plant nutrient uptake for soil-root systems with root hairs. Plant and Soil 70: 403-413.

Jungk, A. and N. Claassen 1997. Ion diffusion in the soil-root system. Advances in Agronomy. 61: 53-109.

Kelly, J. M. and P. A. Mays. 1999. Nutrient supply changes within a growing season in two deciduous forest soils. Soil Science Society of America Journal 63: 226-232.

Kelly, J. M. and S. A. Barber. 1991. Magnesium uptake kinetics in loblolly pine seedlings. Plant and Soil 134: 227-232.

Kelly, J. M., S. A. Barber and G. S. Edwards. 1992. Modelling magnesium, phosphorus, and potassium uptake by loblolly pine seedlings using a Barber-Cushman approach. Plant and Soil 139: 209-218.

Kelly, J. M., A. H. Chappelka and B. G. Lockaby. 1995. Measured and estimated parameters for a model of nutrient uptake by trees. New Zealand Journal of Forestry Science 24: 213-225.

Kelly, J. M. and T. Ericsson. 2003. Assessing the nutrition of juvenile hybrid poplar using a steady state technque and a mechanistic model. Forest Ecology and Management 180: 249-260.

Kelly, J. M., W. R. Graves and A. Aiello. 2000. Nitrate uptake kinetics for rooted cuttings of Acer rubrum L. Plant and Soil 221: 221-230. 
Kelly, J. M. and J. K. Kelly. 2001. Phosphorus and potssium uptake kinetics in red maple seedlings. Forest Science 47: 397-402.

Kelly, J. M., J. D. Scarbrough and P. A. Mays. 2001. Hardwood seedling root and nutrient parameters for a model of nutrient uptake. Journal of Environmental Quality 30: 427-439.

Li, H. and N. B. Comerford. 2000. SSAND Version 1.0, Release 1.06 (10-8-2001) User's Guide. University of Florida. Gainesvilee, FL.

Lodish, H., A. Berk and S. L. Zipusky. 2001. Molecular cell biology. W. H. Freeman, New York.

Marschner, H. 1995. Mineral nutrition of higher plants. 2nd edition. Academic Press, London.

Nye, P. H. and F. H. C. Marriott. 1969. A theoretical study of the distribution of substances around roots resulting from simultaneous diffusion and mass flow. Plant and Soil 30: 459-472.

Nye, P. H. and J. A. Spiers. 1964. Simultaneous diffusion and mass flow to plant roots. p. 535-541 In (editors missing.) Transactions : 8th International Congress of Soil Science, Bucharest, Romania, 31 Aug. -9 Sep. 1964. Publishing House of the Academy of the Socialist Republic of Romania, Rompresfilatelia, Bucharest.

Nye, P. H. and P. B. Tinker. 1977. Solute movement in the soil-root system. University of California Press, Berkeley and Los Angeles.

Oates, K. and S. A. Barber. 1987. NUTRIENT UPTAKE: a microcomputer program to predict nutrient absorption from soil by roots. Journal of Agronomic Education 16: 65-68.

Olsen, S. R., W. D. Kemper and R. D. Jackson. 1962. Phosphate diffusion to plant roots. Soil Science Society of America Proceedings 26: 222-227.

Pfeffer, H., F. Dannel and V. Römheld. 2001. Boron compartmentation in roots of sunflower plants of different boron status: a study using the stable isotopes ${ }^{10} \mathrm{~B}$ and ${ }^{11} \mathrm{~B}$ adopting two independent approaches. Physiologia Plantarum 113: 346-351.

Pypers, P., J. Delrue, J. Diels, E. Smolders and R. Merckx. 2006. Phosphorus intensity determines short-term P uptake by pigeon pea (Cajanus cajan L.) grown in soils with differing P buffering capacity. Plant and Soil 284: 217-227.

Rengel, Z. 1993. Mechanistic simulation models of nutrient uptake: a review. Plant and Soil 152: 161-173.

Sadana, U. S. and N. Claassen. 2000. Manganese dynamics in the rhizosphere and Mn uptake by different crops evaluated by a mechanistic model. Plant and Soil 218: 233238. 
Sadana, U. S., P. Sharma, O. Castañeda, D. Samal and N. Claassen. 2005. Manganese uptake and Mn efficiency of wheat cultivars are related to Mn-uptake kinetics and root growth. Journal of Plant Nutrition and Soil Science 168: 581-589.

Samal, D., U. S. Sadana and A. A. S. Gill. 2003. Mechanistic approach to study manganese influx and its depletion in the rhizosphere of wheat and raya. Communications in Soil Science and Plant Analysis 34: 3033-3044.

Satnam, S. and U. S. Sadana. 2002. Prediction of phosphorus uptake by wheat and its depletion in the rhizosphere using a mechanistic model. Journal of Plant Nutrition 25: 623-633.

Silberbush, M. and S. A. Barber. 1983. Sensitivity of simulated phosphorus uptake to parameters used by a mechanistic-mathematical model. Plant and Soil 74: 93-100.

Singh, B. 2008. Nutrient uptake by hybrid poplar in competition with weed species under growth chamber and field conditions using the soil supply and nutrient demand (SSAND) model. Ph.D. Dissertation University of Saskatchewan, Saskatoon, Canada.

Smethurst, P. J. and N. B. Comerford. 1993a. Potassium and phosphorus uptake by competing pine and grass: observations and model verification. Soil Science Society of America Journal 57: 1602-1610.

Smethurst, P. J. and N. B. Comerford. 1993b. Simulating nutrient uptake by single or competing and contrasting root systems. Soil Science Society of America Journal 57: 1361-1367.

Smethurst, P. J., N. B. Comerford and D. G. Neary. 1993. Predicting the effects of weeds on $\mathrm{K}$ and $\mathrm{P}$ uptake by young slash pine on a Spodosol. Forest Ecology and Management 60: 27-39.

Smethurst, P. J., D. S. Mendham, M. Battaglia and R. Misra. 2004. Simultaneous prediction of nitrogen and phosphorus dynamics in a Eucalyptus nitens plantation using linked CABALA and PCATS models. p. 565-569 In N. M. G. Borralho (ed.) Eucalyptus in a changing world. Proceedings of an International Conference of the WP2.08.03 on Silviculture and Improvement of Eucalypts, Aveiro, Portugal, 11-15 October 2004. IUFRO, Aveiro, Portugal.

Steingrobe, B., N. Claassen and K. M. Syring. 2000. The effect of the function type for describing the soil buffer power on calculated ion transport to roots and nutrient uptake from the soil. Journal of Plant Nutrition and Soil Science-Zeitschrift Fur Pflanzenernahrung Und Bodenkunde 163: 459-465.

Syring, K. M. and N. Claassen. 1995. Estimation of the influx and the radius of the depletion zone developing around a root during nutrient-uptake. Plant and Soil 175: $115-123$. 
Tinker, P. B. and P. H. Nye. 2000. Solute movement in the rhizosphere. Oxford University Press, New York.

Van Rees, K. C. J., N. B. Comerford and W. W. Mcfee. 1990. Modelling potassium uptake by slash pine seedlings from low-potassium-supplying soils. Soil Science Society of America Journal 54: 1413-1421.

Van Rees, K. C. J. and N. B. Comerford. 1990. The role of woody roots of slash pine seedlings in water and potassium absorption. Canadian Journal of Forest Research 20: 1183-1191.

Wang, Z. Y., J. M. Kelly and J. L. Kovar. 2004. Depletion of macro-nutrient from rhizosphere soil solution by juvenile corn, cottonwood, and switchgrass plants. Plant and Soil 270: 213-221.

Williams, M. and R. D. Yanai. 1996. Multi-dimensional sensitivity analysis and ecological implications of a nutrient uptake model. Plant and Soil 180: 311-324.

Yanai, R. D. 1994. A steady-state model of nutrient uptake accounting for newly grown roots. Soil Science Society of America Journal 58: 1562-1571.

Yanai, R. D., H. Majdi and B. B. Park. 2003. Measured and modelled differences in nutrient concentrations between rhizosphere and bulk soil in a Norway spruce stand. Plant and Soil 257: 133-142. 


\title{
Chapter III. NUTRIENT UPTAKE ESTIMATES FOR WOODY SPECIES AS DESCRIBED BY THE NST 3.0, SSAND, AND PCATS MECHANISTIC NUTRIENT UPTAKE MODELS
}

\begin{abstract}
Mechanistic nutrient uptake models have been developed based on the principles of nutrient movement in the soil, nutrient uptake kinetics, and root growth and morphology. There are two major categories of mechanistic models, transient state models with a numerical solution and steady state models. NST 3.0 belongs to the former set of models, while SSAND and PCATS belong to the latter. Because the different approaches to solution between transient and steady state models may lead to different simulation results, and studies using the three models to assess woody species are limited, it would be useful to evaluate the three models by comparing model predictions based on common data sets taken from the literature against the observed measurements. Therefore, the objectives of this study are to: (i) compare the predictions of uptake by the NST 3.0, SSAND, and PCATS models for a suite of nutrients against experimentally measured values, (ii) compare the behavior of the three models using a one dimensional sensitivity analysis; and (iii) compare and contrast the behavior of NST 3.0 and SSAND using a multiple dimensional sensitivity analysis. The predictions of nutrient uptake by the three models using the same data set were diverse, indicating a need to reexamine model structure. Further studies using representative datasets are also needed so that the predictive accuracy of each model can be evaluated. Both types of sensitivity analyses suggested that the effect of soil moisture on simulation can be influential when nutrient concentration in the soil solution $\left(\mathrm{C}_{\mathrm{Li}}\right)$ is low. One dimensional sensitivity analysis also revealed that $\mathrm{I}_{\max }$ negatively influenced estimates of nutrient uptake in the SSAND and PCATS models. Further analysis indicated that this phenomenon was related to the low nutrient supply ability of the soils. The predictions of SSAND under low-nutrient-supply scenarios are generally lower than these of NST 3.0 (the greatest underestimate was 100\%). We suspect that both of these results are artifacts of the steady state models and further studies to improve them are required. Modeling
\end{abstract}


the influence of rhizospheric effects warrants more emphasis because of the longer growth periods and low nutrient supply situations more typical related to woody species.

\section{Introduction}

Mechanistic modeling of nutrient uptake started in the early 1960s when Bouldin (1961) and Olsen et al. (1962) proposed mathematical models to simulate the diffusion of solutes through soils. Models of plant uptake based on the seminal efforts by Nye and Spiers (1964), Nye and Marriot (1969), and Baldwin et al. (1973), and advanced by the subsequent work of Claassen and Barber (1976), Nye and Tinker (1977), Barber and Cushman (1981), Claassen and Steingrobe (1999), and Steingrobe et al. (2000), are becoming important research tools. Mechanistic modeling took a significant step forward with advent of the personal computer as reflected in the work of Oates and Barber (1987), Smethurst and Comerford (1993b), Yanai (1994), Smethurst et al. (2004), and Comerford et al. (2006). Usually, these models consist of three basic components represented by a set of equations that describe (Rengel 1993): (i) solute movement in the soil toward plant roots using the continuity equation that expresses "the change in mass of a substance in a small volume over a small time" (Tinker and Nye 2000); (ii) nutrient uptake kinetics using the Michaelis-Menten equation; and (iii) nutrient uptake as a result of root growth and inter-root competition through the use of root growth and morphology parameters. Depending on the way in which the continuity equation is solved, two major categories of models have evolved, steady state or transient state models (Tinker and Nye 2000). NST 3.0 is an example of a transient state model with a numerical solution, while SSAND and PCATS are steady state models.

Research on several crop species has demonstrated that the predictions of these mechanistic models generally match the observed uptake under situations in which the soil and plant conditions are relatively constant (Barber 1995). However, results with woody species have been more variable (Gillespie and Pope 1990; Van Rees et al. 1990; Smethurst and Comerford 1993b).

One way to evaluate the models is by comparing model predictions with measured values. A second approach is the use of sensitivity analysis. The traditional way to conduct a sensitivity analysis in the modeling context is by changing a single input parameter in the model while keeping the others constant (Silberbush and Barber 1983). Williams and Yanai (1996) suggested this method be called a one dimensional sensitivity analysis. However, because "the relative 
importance of parameters defined this way can depend strongly on the values of the other parameters", Williams and Yanai (1996) developed a multiple dimensional sensitivity analysis in order to study model behavior across a broad range of possible parameter values.

Differences between NST 3.0, SSAND, and PCATS are not well understood in terms of predictive accuracy and model behavior. The different development methods used in the models may lead to different simulations. Research to date related to the use of SSAND and PCATS is limited. Agreement between the uptake predictions of their predecessor model, COMP8, and observed values were not good in low nutrient supply scenarios (Smethurst and Comerford 1993a). Although NST 3.0 has performed well with crop species, no tests have been done with woody species. Because no study has been conducted to compare the efficacy of the three models, it would be beneficial to evaluate the three models by comparing model predictions with nutrient uptake observations using multiple datasets representing various situations taken from the literature and by conducting sensitivity analyses.

Therefore, the objectives of this study are to: (i) compare the predictions of uptake by the NST 3.0, SSAND, and PCATS models for a suite of nutrients against experimentally measured values, (ii) compare the behavior of the three models using a one dimensional sensitivity analysis; and (iii) compare and contrast the behavior of NST 3.0 and SSAND using the multiple dimensional sensitivity analysis approach of Williams and Yanai (1996).

\section{Material and Methods}

Basic principles and model assumptions

Mechanistic nutrient uptake models are very complex nonlinear models. They were developed based on understanding from multiple disciplines including soil chemistry, soil physics, and plant physiology and improved constantly by the advances in these fields. NST 3.0, SSAND, and PCATS belong to two major categories of mechanistic models, and represent the current state of the art. In order to make a successful comparison, it is necessary to review the basic principles and assumptions of these mechanistic models. Table 5 lists the primary symbols and parameters that are used in the mechanistic models described in this paper.

A number of both general and specific assumptions underlie the models.

- The soil is homogeneous and isotropic (Rengel 1993). 
Table 5. List of symbols and definitions used in the NST 3.0, SSAND, and PCATS mechanistic nutrient uptake model equations.

\begin{tabular}{ll}
\hline Symbol & \\
\hline$b$ & buffer power of nutrient \\
$C$ & nutrient concentration in soil \\
$\mathrm{C}_{\mathrm{av}}$ & average nutrient concentration in depletion zone \\
$\mathrm{C}_{\mathrm{L}}$ & nutrient concentration in soil solution \\
$\mathrm{C}_{\mathrm{L} 0}$ & nutrient concentration in soil solution at the root surface \\
$\mathrm{C}_{\mathrm{Li}}$ & initial concentration of the nutrient in the soil solution \\
$\mathrm{C}_{\mathrm{min}}$ & concentration in solution below which net influx ceases \\
$\mathrm{D}$ & diffusion coefficient of solute \\
$\mathrm{D}_{\mathrm{e}}$ & effective diffusion coefficient for the nutrient in the soil \\
$\mathrm{D}_{\mathrm{L}}$ & diffusion coefficient of solute in water \\
$\mathrm{E}$ & nutrient efflux of plant roots \\
$\mathrm{F}$ & flux of solute \\
$\mathrm{F}_{\mathrm{D}}$ & flux of solute by diffusion \\
$\mathrm{F}_{\mathrm{M}}$ & flux of solute by mass flow \\
$\mathrm{f}$ & impedance factor or tortuosity factor \\
$\mathrm{I}$ & net influx of solute \\
$\mathrm{I}_{\mathrm{max}}$ & maximum net influx at high nutrient concentrations \\
$\mathrm{k}$ & rate of root growth \\
$\mathrm{K}_{\mathrm{m}}$ & Michaelis-Menten constant \\
$\mathrm{L}_{0}$ & initial root length \\
$\mathrm{L}_{\mathrm{v}}$ & root length density \\
$\mathrm{r}$ & radial distance in soil from the root surface \\
$\mathrm{r}_{0}$ & mean root radius \\
$\mathrm{r}_{1}$ & half-distance between root axes \\
$\mathrm{t}$ & time \\
$\mathrm{U}$ & the amount of nutrient uptake by a root or root systems \\
$\mathrm{v}$ & mean water influx \\
$\mathrm{v}_{0}$ & mean water influx at root surface \\
$\mathrm{v}_{1}$ & water influx at the distance $\mathrm{r}_{1}$ \\
$\alpha$ & root absorbing power \\
$\theta$ & volumetric soil moisture \\
\hline & \\
\hline &
\end{tabular}


- Nutrients move to the root by a combination of mass flow and diffusion (Barber 1995).

- Roots are smooth cylinders and the nutrient absorbing power is the same over all the cylinders (Barber 1995).

- Mycorrhizae, root hairs, root exudates, or microbial activity on the root surface do not influence nutrient flux (Barber 1995).

- Nutrient uptake can be described by Michaelis-Menten kinetics and the kinetics parameters do not change over time (Barber 1995).

- Influx is independent of the rate of water absorption (Barber 1995)

- For NST 3.0, the soil moisture is essentially constant (Barber 1995). The roots are distributed evenly in the whole soil volume, and no allowance is given for a changing distance among roots as roots grow (Claassen and Steingrobe 1999); A root segment can exploit only a limited volume of soil, and the root is at the center of this cylinder (Claassen and Steingrobe 1999).

- For SSAND and PCATS, Roots are assumed to be parallel and distributed regularly throughout the soil volume (Baldwin 1973).

As a transient state model utilizing a numerical solution, NST 3.0 has been widely used to predict nutrient uptake by various crop species (Sadana and Claassen 2000; Satnam and Sadana 2002; Samal et al. 2003; Sadana et al. 2005; Pypers et al. 2006). However, we are not aware of any studies utilizing this model on a woody species. Transient state models utilizing a numerical solution are a well established approach to mechanistic nutrient uptake models (Tinker and Nye 2000). The Barber-Cushman model is a well-known and widely-used model in this category. NUTRIENT UPTAKE model and NST 1.0 are the personal computer version of the BarberCushman model (Claassen et al. 1986; Oates and Barber 1987). Since NST 3.0 is an improved version of NST 1.0, and all the data sets obtained from the literature for testing model predictive accuracy were developed for use with NUTRIENT UPTAKE model, the principles of NUTRIENT UPTAKE model and NST series are presented.

Nye and Spiers (1964) proposed the continuity equation that described the flux of nutrient in the soil to the root surface: 


$$
\frac{1}{r} \frac{\partial\left(r D \frac{\partial C_{L}}{\partial r}+\frac{v_{0} r_{0} C_{L}}{b}\right)}{\partial r}=\frac{\partial C_{L}}{\partial t}
$$

where $r$ is the radial distance from the root, $D$ is the diffusion coefficient, $C_{L}$ is the nutrient concentration in the soil solution, $\mathrm{v}_{0}$ is the water flux at the root surface, $\mathrm{r}_{0}$ is the average root radius, $b$ is the buffer power of the nutrient, and $t$ is time. Nye and Marriot (1969) defined boundary conditions and solved this equation numerically.

Building on the work of Nye and Marriot (1969), Claassen and Barber (1976), and Cushman (1979a; 1979b), Barber and Cushman (1981) revised the boundary conditions of equation 1 to include inter-root competition for nutrients under both inner and outer boundary conditions:

(1) Inner boundary condition:

$$
t>0, r=r_{0}, F=D b \frac{\partial C_{L}}{\partial r}+v_{0} C_{L}=\frac{\alpha C_{L}}{1+\alpha C_{L} / I_{\max }}-E
$$

Where $\mathrm{F}$ is the flux of the nutrient, $\alpha$ is the root absorbing power, $\mathrm{I}_{\max }$ is maximum net influx at high nutrient concentrations, $\mathrm{E}$ is the nutrient efflux of plant roots, and $\left(\frac{\alpha C_{L}}{1+\frac{\alpha C_{L}}{I_{\max }}}-E\right)$ is a transformation of the Michaelis-Menten equation.

(2) Outer boundary condition:

If there is no inter-root competition,

$$
t>0, r=r_{1}, C_{L}=\text { constant }
$$

If there is inter-root competition,

$$
t>0, r=r_{1}, F=D b \frac{\partial C_{L}}{\partial r}+v_{1} C_{L}=0
$$

where $\mathrm{v}_{1}$ is the water influx at the distance $\mathrm{r}_{1}$.

The boundary conditions incorporated inter-root competition and Michaelis-Menten kinetics. When solved numerically, the enhanced mechanistic model evolved into the Barber-Cushman model. In 1983, Itoh and Barber made a change to the Barber-Cushman model so that it is able to simulate nutrient uptake by root hairs. In 1987, Oates and Barber published NUTRIENT UPTAKE model, which is a personal computer version of the Barber-Cushman model with the revision by Itoh and Barber (1983). In 1986 Claassen et al. published NST 1.0 model, which was based largely on the Barber-Cushman model. Later Claassen and his colleagues developed NST 2.0 and NST 3.0, which were not published in a journal (Claassen, N. Personal communication. 
2009, 31 July). NST 3.0 incorporates the Freundlich isotherm into the model so that the buffer power (b) changes as the nutrient concentration in soil solution changes (Steingrobe et al. 2000).

Steady state models are another major standard category in mechanistic nutrient uptake modeling (Tinker and Nye 2000). Baldwin et al. (1973) and Nye and Tinker (1977) proposed the key equations. Based on their work, Smethurst and Comerford (1993b) developed a model, COMP8 (Competition model version 8), which was able to calculate nutrient uptake between two competing and contrasting root systems. SSAND is a revision and expansion of COMP8 by Comerford et al. (2006). Its main improvements lie in the functions of predicting nutrient uptake as influenced by mycorrhizae and simulation of fertilization effects (Comerford et al. 2006). Based on COMP8 and an earlier version of SSAND, another steady state model, PCATS was developed by Smethurst et al. (2004) to simulate nutrient uptake by a single species. In the following section, the principles of steady state models are briefly described, and the features of COMP8, SSAND and PCATS are introduced.

Based on the continuity equation of Nye and Spiers (1964), Baldwin et al. (1973) and Nye and Tinker (1977) proposed the key equations for the concentration profile around the root, as well as the average concentration for use in a steady state model.

$$
\frac{C_{L r}}{C_{L 0}}=\frac{\alpha}{v_{0}}+\left[1-\frac{\alpha}{v_{0}}\right]\left(\frac{r}{a}\right)^{-\left(\frac{r_{0} v_{0}}{b D}\right)}
$$

Where $\mathrm{C}_{\mathrm{Lr}}$ is the nutrient concentration in soil solution at the distance $\mathrm{r}$ from the root, and $\mathrm{C}_{\mathrm{L} 0}$ is the nutrient concentration in soil solution at the root surface.

By representing the average concentration across the depletion zone with $\mathrm{C}_{\mathrm{av}}$, the relationship between $\mathrm{C}_{\mathrm{av}}$ and $\mathrm{C}_{\mathrm{L} 0}$ can be obtained by

$$
\frac{C_{a v}}{C_{L 0}}=\frac{\alpha}{v_{0}}+\left(1-\frac{\alpha}{v_{0}}\right)\left(\frac{2}{2-\frac{r_{0} v_{0}}{b D}}\right) \frac{\left(\frac{r_{1}}{r_{0}}\right)^{\left(2-\frac{r_{0} v_{0}}{b D}\right)}-1}{\left(\frac{r_{1}}{r_{0}}\right)^{2}-1}
$$

Because the amount of nutrient uptake $\Delta U$ during the time period $\Delta t$ is given by the equation:

$$
\Delta U=2 \pi r_{0} L_{v} \alpha C_{L 0} \Delta t
$$

$\Delta U$ can be calculated using equations 6 and 7 : 


$$
\Delta U=2 \pi r_{0} L_{v} \alpha \Delta t \frac{C_{a v} v_{0}}{\alpha+\left(v_{0}-\alpha\right)\left(\frac{2}{2-\frac{r_{0} v_{0}}{b D}}\right) \frac{\left(\frac{r_{1}}{r_{0}}\right)^{\left(2-\frac{r_{0} v_{0}}{b D}\right)}-1}{\left(\frac{r_{1}}{r_{0}}\right)^{2}-1}}
$$

At time interval $\Delta t_{1}, \mathrm{C}_{\mathrm{av} 1}=\mathrm{C}_{\mathrm{Li}}$. Therefore the new $\mathrm{C}_{\mathrm{av} 2}$ can be calculated from the uptake at time interval $\Delta t_{2}$, and $\mathrm{C}_{\mathrm{L} 02}$ can be calculated from $\mathrm{C}_{\mathrm{av} 2}$. This approach allows any time period to be represented. Finally, the total amount of nutrient uptake can be obtained by summing $\Delta U$ at each time interval.

Another key equation which Smethurst and Comerford (1993b) based the development of COMP8 on is not discussed here because it is related to nutrient uptake by two competing roots. Smethurst and Comerford (1993b) also made the following improvements: (i) "a depletion zone that increased with time until it reached the no-transfer boundary, (ii) an adjustment in concentration to reflect newly encountered solutes in the depletion zone, (iii) a variable root absorbing power $\alpha$ (equation 9) to describe Michaelis-Menten uptake kinetics, and (iv) a routine to account for the competition between two root systems".

$$
\alpha=\frac{I_{\max }}{K_{m}+C_{L 0}-C_{\min }}
$$

Two verification studies with slash pine and weeds were conducted in the same year (Smethurst and Comerford 1993a; Smethurst et al. 1993). However, this model has had little use since 1993 because it was judged to be inadequate under some conditions possibly due to its inability to describe some components of the soil-root system such as root length development, changing soil moisture content, and nutrient input from mineralization (Smethurst and Comerford 1993b; Singh 2008).

Based on COMP8, SSAND included several new functions allowing simulation of nutrient uptake by roots under a variety of conditions such as mycorrhizal roots, fertilization, changing soil water content, nutrients from different soil horizons, and dynamic mineralization rates (Comerford et al. 2006). SSAND includes a sub-routine to calculate the nutrient demand for target plant growth, so that it can provide a recommendation on fertilization by comparing the predicted uptake and demand.

Similar to SSAND, PCATS is able to simulate nutrient uptake by mycorrhizae and uptake influenced by fertilization (Smethurst et al. 2004). However, it can only predict nutrient uptake 
by one species. PCATS shares similar principles with COMP8 and SSAND, but further simplifies the calculation by running on a fixed daily time-step (Smethurst et al. 2004).

Usually transient state models with a numerical solution are considered to be more accurate than steady state models (Smethurst and Comerford 1993b; Yanai 1994). Numerical methods are those that "iteratively solve a system of simultaneous equations developed from approximations of the differential equation for solute transport" (Smethurst and Comerford 1993b). "The steady state approach assumes that the concentration profile around the root can be considered to be in a steady state" (Yanai 1994), which is usually attained after long times (Nye and Spiers 1964). Since natural phenomena are transient, the results obtained using this approach may not be as accurate as the transient state model.

The major advantage of a steady state model over a transient state model lies in "the independence of the mathematical solution to previous condition" during calculation (Yanai 1994) so that steady state models are able to respond to real-time changes in parameters. Transient state models using a numerical solution are also called "deterministic" models (Claassen and Steingrobe 1999) because the simulation does not accept time-varying input (Yanai 1994). For example, soil moisture is not allowed to change during the calculation, though it is unrealistic to think that soil moisture would remain constant in the field.

\section{Data Used for Comparison of NST 3.0, SSAND, and PCATS}

Data were taken from three studies conducted by Kelly et al. (1992), Kelly et al. (2001), and Kelly and Ericsson (2003). The study by Kelly et al. (1992) verified the use of the NUTRIENT UPTAKE model on the simulation of phosphorus, potassium, and magnesium uptake by 1-0 loblolly pine seedlings growing in a modified A horizon soil (Lily series) for 180 days. Two sets of data were taken from this study.

The study by Kelly et al. (2001) largely focused on the influence of environmental factors and plant growth on parameter values used by NUTRIENT UPTAKE model. They measured the model parameters of 1-year-old black cherry, northern red oak, and red maple seedlings in pots with A horizon soils from two forest sites in the Great Smoky Mountains National Park in Tennessee. Two sets of data on red maple grown in the Cove Mountain soil were taken from this study. The study of phosphorus uptake was not included because of the authors did not detect any phosphorus in the soil solution obtained. 
Uptake of nitrate, phosphorus, and potassium by hybrid poplar cuttings was simulated for either 30 or 105 days by Kelly and Ericsson (2003) using the NUTRIENT UPTAKE model. A steady state technique to assure maximal relative growth rate at three fertilizer additions (different amounts of 17-6-12 fertilizer addition equivalent to 0,75 , and $150 \mathrm{~kg} \mathrm{ha}^{-1}$ of nitrogen) were included in the experiment. Nine data sets were taken from this study.

\section{Data transformation}

The inputs for NST 3.0, SSAND, and PCATS differ in some ways from those used for NUTRIENT UPTAKE model. SSAND provides the user great flexibility to define various scenarios. For example, the user of SSAND and PCATS can define more than one soil horizon that the plants explore and can specify different parameters in each horizon. The number of parameters also depends on the way the user collects data. Because all data sets obtained from the studies of Kelly et al. (1992), Kelly et al. (2001), and Kelly and Ericsson (2003) were developed for use with NUTRIENT UPTAKE model, data transformations were required.

Unlike NUTRIENT UPTAKE model which uses a fixed value of buffer power (b), all three models allow users to input parameters to define a sorption equation so that $\mathrm{b}$ can be calculated as the nutrient concentration in the soil solution changes as plant uptake occurs. This function is slightly different among the models. NST 3.0 and PCATS allow the user to define only a Freundlich equation for the absorption isotherm. SSAND uses different adsorption and desorption isotherms, and allows the user to choose either a Freundlich or Langmuir equation to fit these sorption isotherms. Because the studies of Kelly et al. (1992), Kelly et al. (2001), and Kelly and Ericsson (2003) followed the methodology of Barber (1995) and the buffer power of the soil is the nutrient concentration per unit soil volume $(\mathrm{C})$ divided by the concentration in soil solution $\left(\mathrm{C}_{\mathrm{L}}\right)$ :

$$
b=C / C_{L}
$$

The isotherm equations for the three models were set as

$$
C=b * C_{L}
$$

Like NUTRIENT UPTAKE model, NST 3.0 requires the user to input a fixed value for the tortuosity factor (f). SSAND provides several functions that the user can choose to define a formula for calculating $f$ with volumetric soil moisture $\theta$. PCATS works similarly to SSAND in this aspect, except that it provides only one slightly different function. The formulas used in our 
simulation were first proposed by Kovar and Barber (1990). That is, if the soil is $>75 \%$ sand and $\theta<0.15 \mathrm{~m}^{3} \mathrm{~m}^{-3}$ at field capacity,

$$
f=0.25 \theta
$$

Otherwise

$$
f=1.58 \theta-0.172
$$

When an absorption isotherm is introduced into the model, buffer power (b) is no longer fixed and changes as $C_{\mathrm{Li}}$ changes. The effective diffusion coefficient $\left(\mathrm{D}_{\mathrm{e}}\right)$ can also vary during simulation because it is related to b. Since NST 3.0, SSAND, and PCATS require the user to define sorption isotherms, $D_{\mathrm{e}}$ is not an input parameter in these models and is replaced by volumetric soil moisture $(\theta)$ and the diffusion coefficient in water of the nutrient $\left(D_{L}\right)$.

NST 3.0 uses the half distance between root axes $\left(r_{1}\right)$ at the end of the experiment rather than the average $r_{1}$ over the experimental period. SSAND and PCATS do not require the user to input $\mathrm{r}_{1}$. Instead, PCATS requires the input of root length density on a daily basis. SSAND can calculate nutrient uptake by assuming no root growth occurred with a specified root length density, or it can use an Excel file to input daily root length density using the same format as PCATS.

Both SSAND and PCATS require user input on soil bulk density and soil volume. PCATS further requires the user to define the percentage of soil volume that is occupied by roots. Because of the lack of information in the literature, the soil volume was assigned as the pot size in the SSAND simulation, and the percentage of the soil volume that was occupied by roots was assumed to be 1 . The same assumptions were used in the PCATS simulation in order to keep the input the same as SSAND.

Since PCATS is designed specifically for predicting phosphorus uptake by plants, its simulated results $\left(U_{P}\right)$ are calculated as $\mu$ mols of phosphorus uptake during the time period. Therefore, the actual simulated results $(U)$ are transformed with the following formula:

$$
U=U_{P} * \frac{\text { atomic weight of phosphorus }}{\text { atomic weight of the nutrient }}
$$

The values for the parameters used in each model are listed in Tables 6 and 7, values that are not listed are discussed below. For NST 3.0, three parameters (a, b, and c) are used to define the sorption isotherm using the simplified isotherm equation $11, \mathrm{~b}$ equals to the buffer power, while 
Table 6. Parameter values for loblolly pine and red maple based on observations reported by Kelly et al. (1992) and Kelly et al. (2001) used for NST 3.0, SSAND and PCATS simulations.

\begin{tabular}{|c|c|c|c|c|c|}
\hline \multirow{2}{*}{ Parameters } & \multirow{2}{*}{ Units } & \multicolumn{2}{|c|}{$\begin{array}{l}\text { Loblolly pine (Kelly et al. } \\
(1992))\end{array}$} & \multicolumn{2}{|c|}{ Red maple (Kelly et al. (2001)) } \\
\hline & & $\mathrm{K}$ & $\mathrm{P}$ & $\mathrm{NO}_{3}-\mathrm{N}$ & $\mathrm{K}$ \\
\hline $\mathrm{D}_{\mathrm{L}}^{\dagger \dagger \delta}$ & $\mathrm{cm}^{2} \mathrm{~s}^{-1}$ & $1.98 \mathrm{E}-05$ & $8.90 \mathrm{E}-06$ & $1.90 \mathrm{E}-05$ & $1.98 \mathrm{E}-05$ \\
\hline$\theta^{\dagger \neq}$ & unitless & \multicolumn{2}{|c|}{0.062} & \multicolumn{2}{|c|}{0.44} \\
\hline $\mathrm{v}_{0}(\text { or LI rate })^{\dagger \ddagger}$ & $\mathrm{cm} \mathrm{s}^{-1}$ & \multicolumn{2}{|c|}{$5.66 \mathrm{E}-07$} & \multicolumn{2}{|c|}{ 5.17E-06 } \\
\hline $\mathrm{C}_{\mathrm{li}}^{\dagger \dagger}$ & $\mu \mathrm{mol} \mathrm{ml}{ }^{-1}$ & 0.27 & 0.19 & 0.51 & 0.13 \\
\hline $\mathrm{b}^{\dagger \dagger}$ & unitless & 10.55 & 5.84 & 1.35 & 7.02 \\
\hline $\mathrm{I}_{\max }^{\dagger \dagger}$ & $\mu \mathrm{mol} \mathrm{cm}{ }^{-2} \mathrm{~s}^{-1}$ & $1.40 \mathrm{E}-06$ & $2.68 \mathrm{E}-07$ & $3.09 \mathrm{E}-05$ & $3.80 \mathrm{E}-06$ \\
\hline $\mathrm{K}_{\mathrm{m}}^{\dagger *}$ & $\mu \mathrm{mol} \mathrm{ml}{ }^{-1}$ & 0.03 & 0.016 & 0.32 & 10.46 \\
\hline $\mathrm{C}_{\min }^{\dagger \dagger}$ & $\mu \mathrm{mol} \mathrm{ml}{ }^{-1}$ & 0.001 & 0.0006 & 0.001 & 0.003 \\
\hline $\mathrm{r}_{0}^{\dagger \dagger}$ & $\mathrm{cm}$ & \multicolumn{2}{|c|}{0.035} & \multicolumn{2}{|c|}{0.044} \\
\hline $\mathrm{r}_{1}^{\dagger}$ & $\mathrm{cm}$ & \multicolumn{2}{|c|}{1.65} & 0.903 & 1.186 \\
\hline $\mathrm{L}_{0}^{\dagger}$ & $\mathrm{cm}$ & \multicolumn{2}{|c|}{285} & \multicolumn{2}{|c|}{1696} \\
\hline $\mathrm{k}^{\dagger}$ & $\mathrm{cm} \mathrm{day}^{-1}$ & \multicolumn{2}{|c|}{14} & \multicolumn{2}{|c|}{41.04} \\
\hline simulated time $\dagger \neq$ & day & \multicolumn{2}{|c|}{180} & 30 & 176 \\
\hline Soil volume & $\mathrm{cm}^{3}$ & \multicolumn{2}{|c|}{24000} & \multicolumn{2}{|c|}{7500} \\
\hline Bulk density ${ }^{\ddagger}$ & $\mathrm{g} \mathrm{cm}^{-3}$ & \multicolumn{2}{|c|}{0.75} & \multicolumn{2}{|c|}{0.74} \\
\hline
\end{tabular}

$\dagger$ parameters used by NST 3.0

\$ parameters used by SSAND and PCATS

$\S$ The values of $D_{L}$ for nitrate and potassium were taken from Parsons (1959), and that of phosphorus from Edwards and Huffman (1959). 
Table 7. Parameter values for hybrid poplar based on observations reported by Kelly and Ericsson (2003) used for NST 3.0, SSAND and PCATS simulations.

\begin{tabular}{|c|c|c|c|c|c|c|c|c|c|c|}
\hline \multirow{2}{*}{ Parameters } & \multirow{2}{*}{ Units } & \multicolumn{3}{|c|}{ No fertilizer addition } & \multicolumn{3}{|c|}{$75 \mathrm{~kg} \mathrm{ha}^{-1}$ of fertilizer addition } & \multicolumn{3}{|c|}{$150 \mathrm{~kg} \mathrm{ha}^{-1}$ of fertilizer addition } \\
\hline & & $\mathrm{NO}_{3}-\mathrm{N}$ & $\mathrm{P}$ & $\mathrm{K}$ & $\mathrm{NO}_{3}-\mathrm{N}$ & $\mathrm{P}$ & $\mathrm{K}$ & $\mathrm{NO}_{3}-\mathrm{N}$ & $\mathrm{P}$ & $\mathrm{K}$ \\
\hline $\mathrm{D}_{\mathrm{L}}^{\dagger \dagger \S}$ & $\mathrm{cm}^{2} \mathrm{~s}^{-1}$ & $1.90 \mathrm{E}-05$ & $8.90 \mathrm{E}-06$ & $1.98 \mathrm{E}-05$ & $1.90 \mathrm{E}-05$ & $8.90 \mathrm{E}-06$ & $1.98 \mathrm{E}-05$ & $1.90 \mathrm{E}-05$ & $8.90 \mathrm{E}-06$ & $1.98 \mathrm{E}-05$ \\
\hline$\theta^{\dagger \neq}$ & unitless & \multicolumn{3}{|c|}{0.27} & \multicolumn{3}{|c|}{0.28} & \multicolumn{3}{|c|}{0.28} \\
\hline $\mathrm{v}_{0}(\text { or LI rate })^{\dagger \dagger}$ & $\mathrm{cm} \mathrm{s}^{-1}$ & \multicolumn{3}{|c|}{$7.46 \mathrm{E}-07$} & \multicolumn{3}{|c|}{$7.46 \mathrm{E}-07$} & \multicolumn{3}{|c|}{$7.46 \mathrm{E}-07$} \\
\hline $\mathrm{C}_{\mathrm{Li}}^{\dagger *}$ & $\mu \mathrm{mol} \mathrm{ml}{ }^{-1}$ & 0.0761 & 0.0021 & 0.0963 & 1.52 & 0.0086 & 0.217 & 2.31 & 0.0388 & 0.519 \\
\hline$b^{\dagger+}$ & unitless & 1.14 & 180.5 & 5.095 & 1.98 & 52.23 & 2.62 & 1.42 & 15.41 & 1.4 \\
\hline$I_{\max }^{\dagger+}$ & $\mu \mathrm{mol} \mathrm{cm} \mathrm{s}^{-2}$ & $2.85 \mathrm{E}-05$ & $1.51 \mathrm{E}-06$ & $1.76 \mathrm{E}-05$ & $2.85 \mathrm{E}-05$ & $1.51 \mathrm{E}-06$ & $1.76 \mathrm{E}-05$ & $2.85 \mathrm{E}-05$ & $1.51 \mathrm{E}-06$ & $1.76 \mathrm{E}-05$ \\
\hline $\mathrm{K}_{\mathrm{m}}^{\dagger \dagger}$ & $\mu \mathrm{mol} \mathrm{ml} l^{-1}$ & 0.712 & 0.00087 & 0.0269 & 0.712 & 0.00087 & 0.0269 & 0.712 & 0.00087 & 0.0269 \\
\hline $\mathrm{C}_{\min }^{\dagger \ddagger}$ & $\mu \mathrm{mol} \mathrm{ml}{ }^{-1}$ & 0.001 & 0.001 & 0.003 & 0.001 & 0.001 & 0.003 & 0.001 & 0.001 & 0.003 \\
\hline $\mathrm{r}_{0}^{\dagger \dagger}$ & $\mathrm{cm}$ & \multicolumn{3}{|c|}{0.02} & \multicolumn{3}{|c|}{0.02} & \multicolumn{3}{|c|}{0.02} \\
\hline $\mathrm{r}_{1}^{\dagger}$ & $\mathrm{cm}$ & \multicolumn{3}{|c|}{0.42} & \multicolumn{3}{|c|}{0.26} & \multicolumn{3}{|c|}{0.26} \\
\hline $\mathrm{L}_{0}^{\dagger}$ & $\mathrm{cm}$ & \multicolumn{3}{|c|}{1094} & \multicolumn{3}{|c|}{779} & \multicolumn{3}{|c|}{976} \\
\hline $\mathrm{k}^{\dagger}$ & $\mathrm{cm}_{\text {day }}{ }^{-1}$ & \multicolumn{3}{|c|}{29.98} & \multicolumn{3}{|c|}{97.63} & \multicolumn{3}{|c|}{94.18} \\
\hline $\begin{array}{l}\text { Simulation } \\
\text { time }\end{array}$ & day & \multicolumn{3}{|c|}{105} & \multicolumn{3}{|c|}{105} & \multicolumn{3}{|c|}{105} \\
\hline Soil volume $e^{\ddagger}$ & $\mathrm{cm}^{3}$ & \multicolumn{3}{|c|}{2357} & \multicolumn{3}{|c|}{2357} & \multicolumn{3}{|c|}{2357} \\
\hline Bulk density & $\mathrm{g} \mathrm{cm}^{-3}$ & \multicolumn{3}{|c|}{1.4} & \multicolumn{3}{|c|}{1.41} & \multicolumn{3}{|c|}{1.4} \\
\hline
\end{tabular}

$\dagger$ parameters used by NST 3.0

¥ parameters used by SSAND and PCATS

$\S$ The values of $D_{L}$ for nitrate and potassium were taken from Parsons (1959), and that of phosphorus from Edwards and Huffman (1959). 
a and $\mathrm{c}$ were set as 1 and 0 for every run. The number of compartments used for numerical calculations was set to 40 for each run. For SSAND, the adsorption and desorption isotherm were assumed to be the same. The Freundlich equation was chosen as the adsorption and desorption type, and the same simplified isotherm equation was used. Equation 12 or 13 was used to define the impedance factor (f), depending on volumetric soil moisture and soil texture. For PCATS, the parameters for the sorption isotherm were set the same as in the other two models. Because the unique function provided by PCATS for calculating impedance factor is different, the value of the parameter of the impedance factor equation was adjusted so that the calculated impedance factors of PCATS were the same as the others. For both SSAND and PCATS, which require the user to define root length density day by day, the root length density for the first day was calculated by dividing initial root length by soil volume. For subsequent days the root length density increases linearly with the step value equal to the root growth rate $\left(\mathrm{cm} \mathrm{day}^{-1}\right)$ divided by soil volume.

\section{Methods of sensitivity analysis}

The traditional or one dimensional sensitivity analysis was first used to by Silberbush and Barber (1983) to show the influence of different parameters on model simulations. It was accomplished by changing a single model input parameter while keeping the others constant (Silberbush and Barber 1983). By plotting the change ratio of the parameters compared to their original values on the horizontal axis, and the predicted uptake to the original prediction on the vertical axis, it is possible to evaluate the importance of each parameter by the slope of the lines on the graph. This procedure has been largely followed in subsequent analyses.

Following the methodology developed by Silberbush and Barber (1983), a one dimensional sensitivity analysis was conducted using the data of Kelly et al. (1992) for potassium uptake by loblolly pine seedlings. Each of the parameters was changed by a factor of $0.5,0.75,1.25,1.5$, or 2 times the original level while the remaining parameters were held constant. Those parameters that are dependent on other parameters were not included in the sensitivity analysis. Claassen and Steingrobe (1999) suggested doing sensitivity analysis with the $\mathrm{C}_{\mathrm{Li}}$ and $\mathrm{b}$ combined. Since an isotherm equation for the Kelly et al. (1992) study was not available, and the simplified relationship between $C_{L}$ and $b$ (equation 11) is not theoretically accurate, the sensitivity analysis 
was done using individual $\mathrm{C}_{\mathrm{Li}}$ and $\mathrm{b}$. Therefore, ten parameters were evaluated in the one dimensional sensitivity analysis of each model.

Yanai (1994) proposed the concept of multiple dimensional sensitivity analysis and conducted several two dimensional sensitivity analyses using the steady state model developed by Baldwin et al. (1973) and Nye and Tinker (1977). Williams and Yanai (1996) conducted a multiple dimensional sensitivity analysis using a simplified steady state model across a range of values described in the literature. By changing each parameter at 4 levels, 16,384 parameter datasets were created. Using ANOVA, they identified the average nutrient concentration in the soil solution $\left(\mathrm{C}_{\mathrm{av}}\right)$, maximal rate of nutrient uptake $\left(\mathrm{I}_{\max }\right)$, root radius $\left(\mathrm{r}_{0}\right)$, and the effective diffusion coefficient $\left(D_{e}\right)$, to be the most important parameters that control uptake per unit length of root (Williams and Yanai 1996). Root radius $r_{0}$ becomes less important when uptake rates are expressed on a surface basis (Williams and Yanai 1996). They then represented selected parameters at 5 levels and plotted the response surface using a series of graphs. The response surfaces developed using this method indicated clear relationships between the selected parameters.

Because SSAND and PCATS share similar principles in modeling and response patterns in the one dimensional sensitivity analysis, only SSAND and NST 3.0 were compared using the multiple dimensional sensitivity analysis. Results obtained from the one dimensional sensitivity analysis indicated that $\mathrm{C}_{\mathrm{Li}}, \theta, \mathrm{k}, \mathrm{r}_{0}$, and $\mathrm{v}_{0}$ were the most influential parameters. Williams and Yanai (1996) found that $\mathrm{C}_{\mathrm{Li}}$ (or $\mathrm{C}_{\mathrm{av}}$ ), $\mathrm{D}_{\mathrm{e}}$, and $\mathrm{I}_{\max }$ were the most influential parameters in their multiple dimensional sensitivity analysis with a simplified steady state model. Therefore, $\mathrm{C}_{\mathrm{Li}}$ and $\theta$ were chosen for further evaluation in the current study because of their prominent effects in the one dimensional sensitivity analysis. Williams and Yanai (1996) did not take root growth (k) or other root morphological parameters into account. But studies on modeling of nutrient uptake by woody species (Van Rees et al. 1990; Smethurst and Comerford 1993b; Comerford et al. 2006; Singh 2008), including our own one dimensional sensitivity analysis, showed that $\mathrm{k}$ was an important parameter for nutrient uptake by woody species. Because all three models simulate nutrient uptake on a surface area basis, plus the fact that the range of average root radius $\left(\mathrm{r}_{0}\right)$ for a species is narrow, $\mathrm{r}_{0}$ was not included in the current multiple dimensional sensitivity analysis. Although $\mathrm{v}_{0}$ is among the most influential parameters in our one dimensional sensitivity analysis, 
it is not included in the multiple dimensional sensitivity analysis because the uptake of potassium is mainly by diffusion (Barber 1995), the importance of $\mathrm{v}_{0}$, a major parameter for mass flow, is not as important. While Williams and Yanai (1996) defined $\mathrm{I}_{\max }$ as one of the most influential parameters, the range of $\mathrm{I}_{\max }$ for loblolly and slash pine was narrow, from $1.4 \mathrm{E}-6 \mu \mathrm{mol} \mathrm{cm} \mathrm{cm}^{-2} \mathrm{~s}^{-1}$ (Kelly et al. 1992) to $3.65 \mathrm{E}-6 \mu \mathrm{mol} \mathrm{cm} \mathrm{c}^{-2} \mathrm{~s}^{-1}$ (Kelly et al. 1995). Although its actual range may be much wider, it is hard to artificially define a range for this parameter. Therefore, $I_{\max }$ was excluded in the multiple dimensional sensitivity analysis. As a result, $\mathrm{C}_{\mathrm{Li}}, \theta$, and $\mathrm{k}$ were selected as the three parameters for evaluating the multiple dimensional sensitivity analysis.

The ranges of values for these parameters were taken from the literature. Because the number of studies on measuring model parameters of loblolly pine is limited, data on slash pine were included to build reasonably representative ranges of the three parameters. The values and sources of the data are listed in Tables 8, 9, and 10. Based on these values, the range for volumetric soil moisture $(\theta)$ was 0.06 to 0.4 , the range for nutrient concentration in the soil solution $\left(\mathrm{C}_{\mathrm{Li}}\right)$ was $0.028 \mu \mathrm{mol} \mathrm{ml}{ }^{-1}$ to $8.54 \mu \mathrm{mol} \mathrm{ml}^{-1}$, and the range for root growth rate $(\mathrm{k})$ was $1 \mathrm{~cm} \mathrm{day}^{-1}$ to $39.3 \mathrm{~cm} \mathrm{day}^{-1}$.

Each of the three parameters was varied linearly at five levels across the range, giving 125 "observations" in the data set for each of the two models. Using the obtained results, two graphical representations similar to those of Williams and Yanai (1996) were developed to show the relationship of the parameters and their influences on the simulations.

\section{Results and Discussion}

\section{Calculation of uptake using data taken from the literature}

Most model simulations underpredict nutrient uptake by $2 \%$ to $100 \%$ (Table 11). Five simulations of potassium uptake were run with NST 3.0, SSAND, and PCATS (Figure 1). For four out of the five simulations NST 3.0 and PCATS predicted 8 to 54\% of the observed uptake. The prediction of uptake by hybrid poplar under the no fertilizer treatment was $125 \%$ and $83 \%$ for NST 3.0 and PCATS, respectively. SSAND predicted 7 to $50 \%$ of the observed uptake in all simulations. 
Table 8. Literature values for soil moisture $(\theta)$ taken from field, nursery, and greenhouse studies of loblolly and slash pine.

\begin{tabular}{lll}
\hline Species and study type & $\theta$ & Data source \\
\hline Slash pine, field study & $0.24-0.3$ & (Van Rees et al. 1990) \\
Slash pine, nursery study & $0.12-0.17$ & (Van Rees et al. 1990) \\
Slash pine, field study, soil depth measured: 0-10 cm & $0.1-0.3$ & (Smethurst et al. 1993) \\
Slash pine, field study, soil depth measured: 10-26 cm & $0.1-0.4$ & (Smethurst et al. 1993) \\
Slash pine, field study, soil depth measured: 26-50 cm & $0.2-0.4$ & (Smethurst et al. 1993) \\
Slash pine, field study, soil depth measured: 50-70 cm & $0.3-0.4$ & (Smethurst et al. 1993) \\
Slash pine, field study & $0.17-0.23$ & (Smethurst and \\
& & Comerford 1993a) \\
Loblolly pine, field study & 0.15 & (Comerford et al. 2006) \\
Loblolly pine, greenhouse study & 0.062 & (Kelly et al. 1992) \\
\hline
\end{tabular}

Table 9. Literature values for potassium concentration in soil solution $\left(\mathrm{C}_{\mathrm{Li}}\right)$ taken from field, nursery, and greenhouse studies of loblolly and slash pine.

\begin{tabular}{lll}
\hline Species & $\mathrm{C}_{\mathrm{Li}}\left(\mu \mathrm{mol} \mathrm{ml}^{-1}\right)$ & Data source \\
\hline Loblolly pine & 0.27 & (Kelly et al. 1992) \\
Loblolly pine & $0.99-8.54$ & (Kelly et al. 1995) \\
Slash pine & $0.035-0.203$ & (Van Rees et al. 1990) \\
Slash pine & $0.0382-0.338$ & (Smethurst and Comerford 1993a) \\
Slash pine & $0-0.46$ & (Smethurst et al. 1993) \\
\hline
\end{tabular}

Table 10. Literature values of root growth rate $(\mathrm{k})$ taken from field, nursery, and greenhouse studies of loblolly and slash pine.

\begin{tabular}{lll}
\hline Species & $\mathrm{k}\left(\mathrm{cm} \mathrm{s}^{-1}\right)$ & Data source \\
\hline Slash pine & $0.000012-0.000184$ & (Van Rees et al. 1990) \\
Slash pine & $0.000064-0.000455$ & (Van Rees and Comerford 1990) \\
Loblolly pine & $0.00004-0.00013$ & (Kelly et al. 1995) \\
Loblolly pine & 0.000162 & (Kelly et al. 1992) \\
\hline
\end{tabular}


Four simulations of nitrate uptake were run with the three models (Figure 2). The percentages for the model predictions divided by the observed uptake for each model is relatively constant. NST 3.0 and SSAND underpredicted nitrate uptake by about 50\%. PCATS predicted nitrate uptake by hybrid poplar in the three fertilizer treatments at $98 \%, 98 \%$, and $85 \%$ of the observed. Red maple uptake of nitrate as described by PCATS was $61 \%$ of the observed uptake.

Four simulations of phosphorus uptake were run with each model (Figure 3). SSAND and PCATS responded very similar and predicted $20 \%$ of the observed uptake in the loblolly pine study, and less than $1 \%$ of the observed uptake in the hybrid poplar study. On the other hand, NST 3.0 predicted $61 \%$ of the observed phosphorus uptake for the loblolly pine study. The prediction by NST 3.0 of phosphorus uptake by hybrid poplar improved as the fertilizer addition increased and the best prediction (110\% of the observed uptake) occurred with the highest fertilizer addition.

NST 3.0, SSAND, and PCATS produced diverse results using the same data (Table 11). For nitrate uptake simulation, PCATS had the closest estimates to the observed uptake, while the performance of NST 3.0 and SSAND are similar. For phosphorus uptake simulation, the performance of NST 3.0 was greatly improved when applied to situations with fertilization, and this was in accordance with the observation of Van Rees et al. (1990) that the Barber-Cushman model worked well in the tree nursery when fertilizers were added. Both SSAND and PCATS predicted phosphorus uptake of hybrid poplar to be less than $1 \mu$ mol, while the observed uptake ranges from $52 \mu \mathrm{mol}$ to more than $1000 \mu \mathrm{mol}$. No obvious pattern was observed in the simulations of potassium uptake by the three models.

In an earlier model comparison study, Van Rees et al. (1990) evaluated potassium uptake by slash pine seedlings growing in a greenhouse, a tree nursery, and the field using the BarberCushman model and the Baldwin-Nye-Tinker model. The authors found that the simulated uptake of the latter model was $5 \%$ higher than the former in all of their studies. As successors of the Barber-Cushman and Baldwin-Nye-Tinker models, NST 3.0, SSAND, and PCATS produced simulated results with a much lower level of agreement.

Although NST 3.0 and PCATS performed relatively well with some runs, there was not a general pattern in the performance of the models in predicting major nutrient uptake in the three studies of coniferous and deciduous species taken from the literature. For example, potassium is 
Table 11. Observed uptake of $\mathrm{NO}_{3}-\mathrm{N}, \mathrm{P}$, and $\mathrm{K}$ compared to simulated uptake as predicted by NST 3.0, SSAND, and PCATS using data from Kelly et al. (1992), Kelly et al. (2001), and Kelly and Ericsson (2003). The percentages represent the degree of correspondence between the simulated and observed uptake value.

\begin{tabular}{|c|c|c|c|c|c|c|c|c|}
\hline \multirow{2}{*}{ Experiments } & \multirow{2}{*}{ Nutrient } & Observed & \multicolumn{6}{|c|}{ Simulated uptake ( $\mu \mathrm{mol})$} \\
\hline & & $(\mu \mathrm{mol})$ & \multicolumn{2}{|c|}{ NST 3.0} & \multicolumn{2}{|c|}{ SSAND } & \multicolumn{2}{|c|}{ PCATS } \\
\hline \multicolumn{9}{|c|}{ Loblolly pine (simulation time: 180 days) } \\
\hline & $\mathrm{K}$ & 6663 & 1020 & $15 \%$ & 466 & $7 \%$ & 510 & $8 \%$ \\
\hline & $\mathrm{P}$ & 1332 & 596 & $45 \%$ & 265 & $20 \%$ & 270 & $20 \%$ \\
\hline
\end{tabular}

Red maple (simulation time for N: 30 days; for K: 176 days)

$\begin{array}{lrrrrrrr}\mathrm{NO}_{3}-\mathrm{N} & 8810 & 4160 & 47 \% & 4277 & 49 \% & 5370 & 61 \% \\ \mathrm{~K} & 1890 & 983 & 52 \% & 950 & 50 \% & 1016 & 54 \%\end{array}$

Hybrid poplar (simulation time: 105 days)

\begin{tabular}{llrrrrrrr}
$\begin{array}{l}0 \mathrm{~kg} \mathrm{ha}^{-1} \text { of } \\
\text { fertilizer }\end{array}$ & $\mathrm{NO}_{3}-\mathrm{N}$ & 346 & 167 & $48 \%$ & 216 & $62 \%$ & 309 & $89 \%$ \\
addition & $\mathrm{P}$ & 170 & 52.3 & $31 \%$ & 0 & $0 \%$ & 0.0004 & $0 \%$ \\
& $\mathrm{~K}$ & 719 & 900 & $125 \%$ & 158 & $22 \%$ & 600 & $83 \%$ \\
$75 \mathrm{~kg} \mathrm{ha}^{-1}$ of & $\mathrm{NO}_{3}-\mathrm{N}$ & 11000 & 6000 & $55 \%$ & 5411 & $49 \%$ & 10814 & $98 \%$ \\
$\begin{array}{l}\text { fertilizer } \\
\text { addition }\end{array}$ & $\mathrm{P}$ & 581 & 489 & $84 \%$ & 0.05 & $0 \%$ & 0.001 & $0 \%$ \\
& $\mathrm{~K}$ & 4302 & 1090 & $25 \%$ & 662 & $15 \%$ & 1562 & $36 \%$ \\
$\begin{array}{l}150 \mathrm{~kg} \mathrm{ha}^{-1} \\
\text { of fertilizer }\end{array}$ & $\mathrm{NO}_{3}-\mathrm{N}$ & 14429 & 6590 & $46 \%$ & 6701 & $46 \%$ & 12235 & $85 \%$ \\
addition & $\mathrm{P}$ & 940 & 1030 & $110 \%$ & 1.01 & $0 \%$ & 0.0006 & $0 \%$ \\
& $\mathrm{~K}$ & 5624 & 1380 & $25 \%$ & 1364 & $24 \%$ & 2467 & $44 \%$ \\
\hline
\end{tabular}




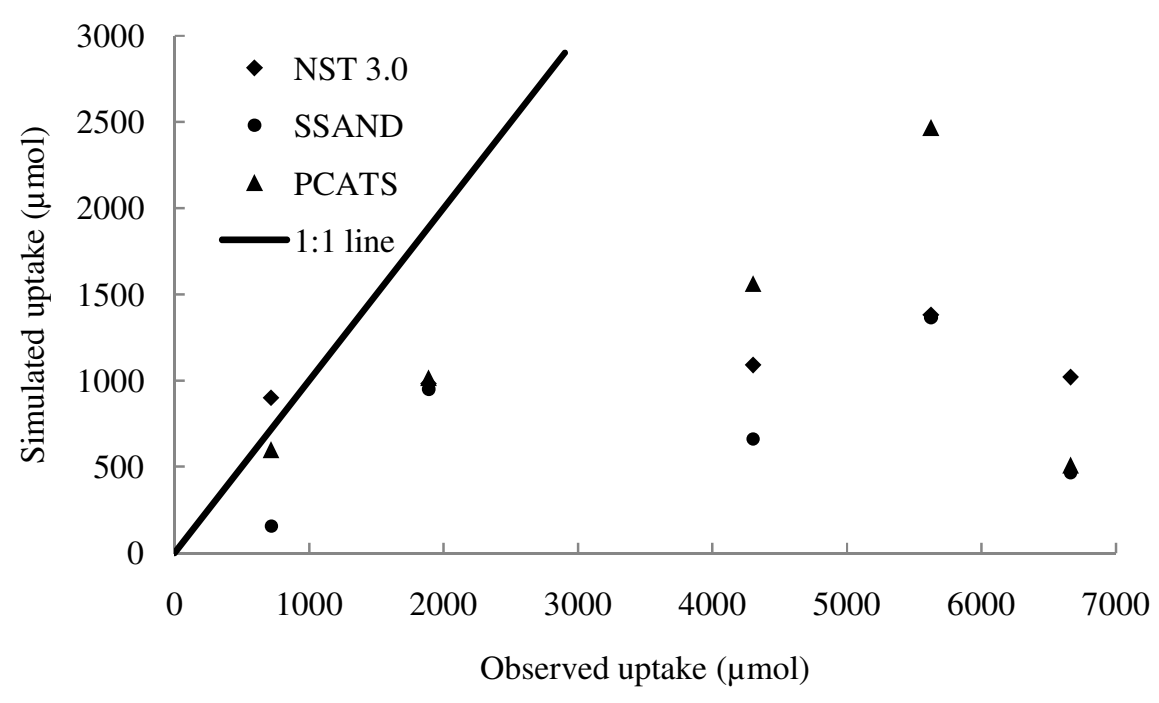

Figure 1. Comparison of predicted potassium uptake by the NST 3.0, SSAND, and PCATS models and observed potassium uptake using data from the studies by Kelly et al. (1992), Kelly et al. (2001), and Kelly and Ericsson (2003).

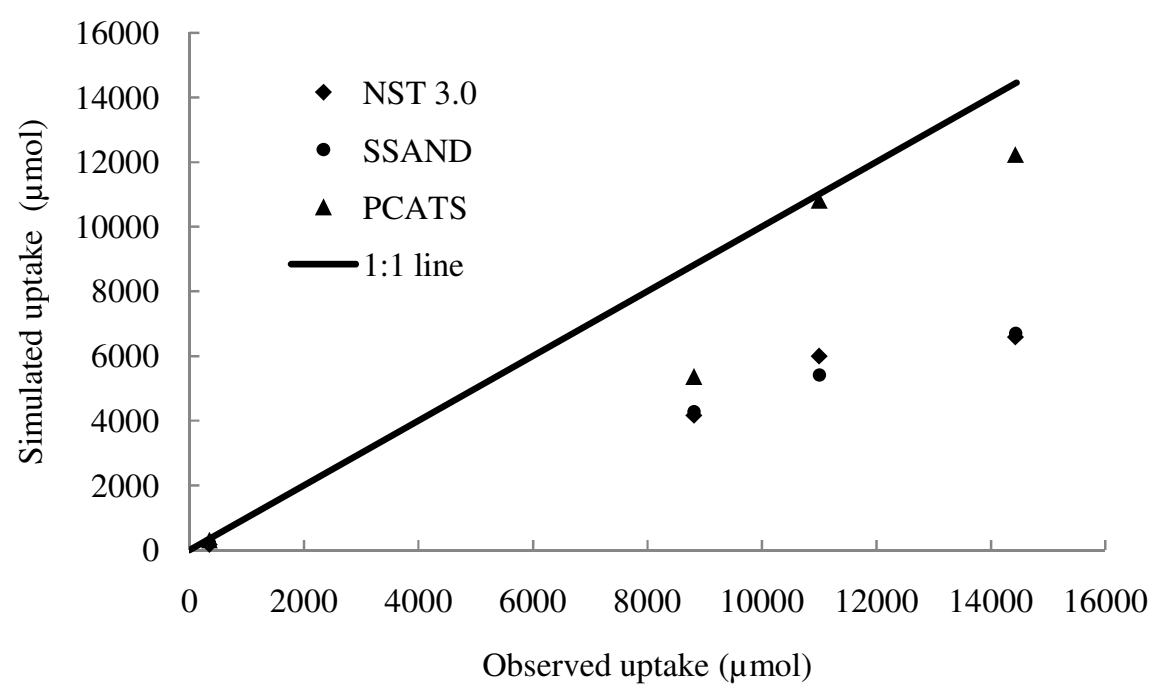

Figure 2. Comparison of predicted nitrate uptake by the NST 3.0, SSAND, and PCATS models and observed nitrate uptake using data from the studies by Kelly et al. (1992), Kelly et al. (2001), and Kelly and Ericsson (2003). 


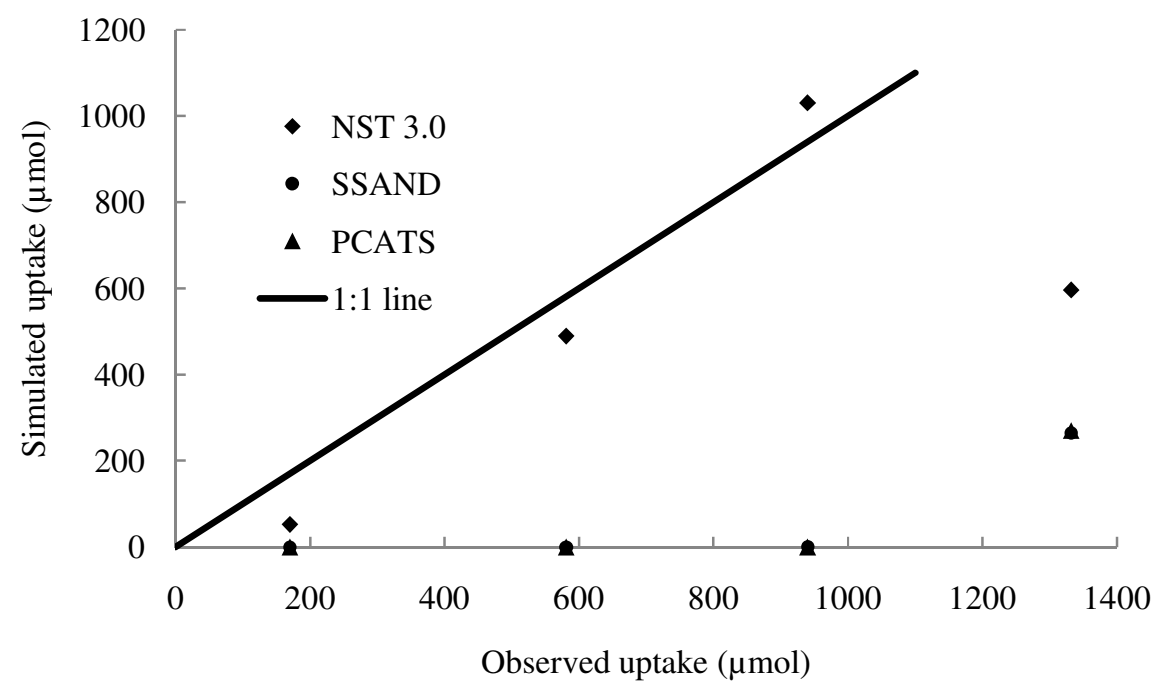

Figure 3. Comparison of predicted phosphorus uptake by the NST 3.0, SSAND, and PCATS models and observed phosphorus uptake using data from the studies by Kelly et al. (1992), Kelly et al. (2001), and Kelly and Ericsson (2003). 
considered to be easier to model than other major nutrients because the components of the potassium cycle in the soil are less complex than nitrogen and its reactions with soil particles or root surfaces are simpler than phosphorus (Tinker and Nye 2000). But the ranges of the percentages of the predicted against observed values by the three models (Table 11) were wide. The fact that the best simulations of NST 3.0 and SSAND occurred in the hybrid poplar study under the no fertilizer treatment contradicts the opinion that mechanistic nutrient models work better under the conditions when soil supply of nutrients is abundant (Van Rees et al. 1990).

Therefore, our study indicates that the prediction of nutrient uptake by NST 3.0 SSAND, and PCATS using the same dataset can be diverse, but it is unclear that why such differences occurred. The lack of estimates on mycorrhizal uptake of nutrients may be an important reason that most simulations underestimated nutrient uptake. Further studies producing representative datasets that both reflect soil and plant characteristics of woody species scenarios are required. Sensitivity analysis

$\underline{\text { One dimensional sensitivity analysis }}$

SSAND and PCATS produce similar patterns in the one dimensional sensitivity analysis (Figures 4 and 5). Listed in order of their importance, the most influential parameters were: $\theta>$ $\mathrm{C}_{\mathrm{Li}}>\mathrm{k}>\mathrm{v}_{0}>\mathrm{r}_{0}$. The analysis also shows that both $\mathrm{I}_{\max }$ and $\mathrm{C}_{\min }$ have similar negative influences on uptake estimates from the two models. For example, increasing $\mathrm{I}_{\max }$ by a factor of 2 decreases the predicted uptake by $35 \%$ and $26 \%$ for SSAND and PCATS, respectively. The change ratios for $\theta, C_{L i}, v_{0}, K_{m}, C_{\min }$, and $I_{\max }$ in SSAND indicate a greater influence on simulated results than those of PCATS. The influence of $k, L_{0}$, and $b$ on the simulated results of the two models was almost the same. Only the influence of $r_{0}$ is less in SSAND than in PCATS (Figures 4 and 5).

The one dimensional sensitivity analysis response of NST 3.0 is different from those of SSAND and PCATS (Figure 6). If listed in the order of significance, the most influential parameters in this sensitivity analysis of NST 3.0 were $\mathrm{C}_{\mathrm{Li}}>\mathrm{r}_{0}=\mathrm{k}>\theta>\mathrm{v}_{0}$. Note that the influence of $\theta$ is not as prominent in NST 3.0 as it is in SSAND and PCATS. The uptake kinetics parameters $\left(\mathrm{I}_{\max }, \mathrm{K}_{\mathrm{m}}\right.$, and $\left.\mathrm{C}_{\min }\right)$ have no influence on NST 3.0 simulations, while for SSAND and PCATS, $I_{\max }$ and $C_{\min }$ had equally significant negative influences and $K_{m}$ had a slight positive influence. Finally, NST 3.0 is the least sensitive model of the three to changes in parameter values. For example, if the value of a parameter is increased by a factor of 2 , the subsequent 
change ratio of results for NST 3.0 ranges from 1 to 2, while that of SSAND ranges from 0.65 to 2.55, and PCATS ranges from 0.74 to 2.42 .

Williams and Yanai (1996) explained the interactions of soil and plant factors in controlling nutrient uptake by "distinguishing whether the rate of nutrient uptake is more limited by the potential rate of nutrient delivery to the root, which depends on soil properties, or by the potential rate of nutrient uptake into the root, which depends on root physiology". In this one dimensional sensitivity analysis of NST 3.0, SSAND, and PCATS for potassium uptake by loblolly pine seedlings, the uptake kinetics parameters either have little or negative influences, and nutrient concentration in soil solution and volumetric soil moisture were among the most influential parameters. Therefore, it appears that potassium uptake by loblolly pine seedlings taken from Kelly et al. (1992) was limited mainly by soil nutrient supply.

The influence of volumetric soil moisture, as represented by $\theta$, is a relatively new parameter in the model sensitivity analysis. It is included in NST 3.0, SSAND, and PCATS, but was not used in the NUTRIENT UTPAKE model. Most nutrient uptake studies using SSAND or NST 3.0 exclude $\theta$ in the sensitivity analysis (Sadana and Claassen 1999; Sadana and Claassen 2000; Gill et al. 2005; Comerford et al. 2006). There are two studies where $\theta$ was included in the sensitivity analysis. These authors found that $\theta$ was among the most influential parameters in both studies (Smethurst and Comerford 1993b; Singh and Sadana 2002). Williams and Yanai (1996) identified $C_{a v}, I_{\max }$, and $D_{e}$ as the most influential parameters in their multiple dimensional sensitivity analysis on a root surface area basis with a simplified steady state model. Because $D_{e}=f \theta D_{L} / b$, the value of $D_{\mathrm{L}}$ is relatively fixed, and $\mathrm{f}$ is a function of $\theta$, the parameters replacing $D_{\mathrm{e}}$ in NST 3.0, SSAND, and PCATS include $\theta$ and $b$. From the equation we also notice that $D_{e}$ is quadratically related to $\theta$. And this may explain why $\theta$ is more influential than $b$ in the sensitivity analysis.

The negative influence of $\mathrm{I}_{\max }$ on simulated results in the one dimensional sensitivity analysis of SSAND and PCATS is surprising. No similar reports have been found. Three studies on nutrient uptake by woody species with a steady state model are available. Smethurst and Comerford (1993b) and Comerford et al. (2006) found no negative influence of $I_{\max }$ in COMP8 and SSAND simulations. Singh (2008) reported on the use of SSAND to simulate ammonium, nitrate, phosphorus, and potassium uptake by hybrid poplar growing on two soils. The study used 


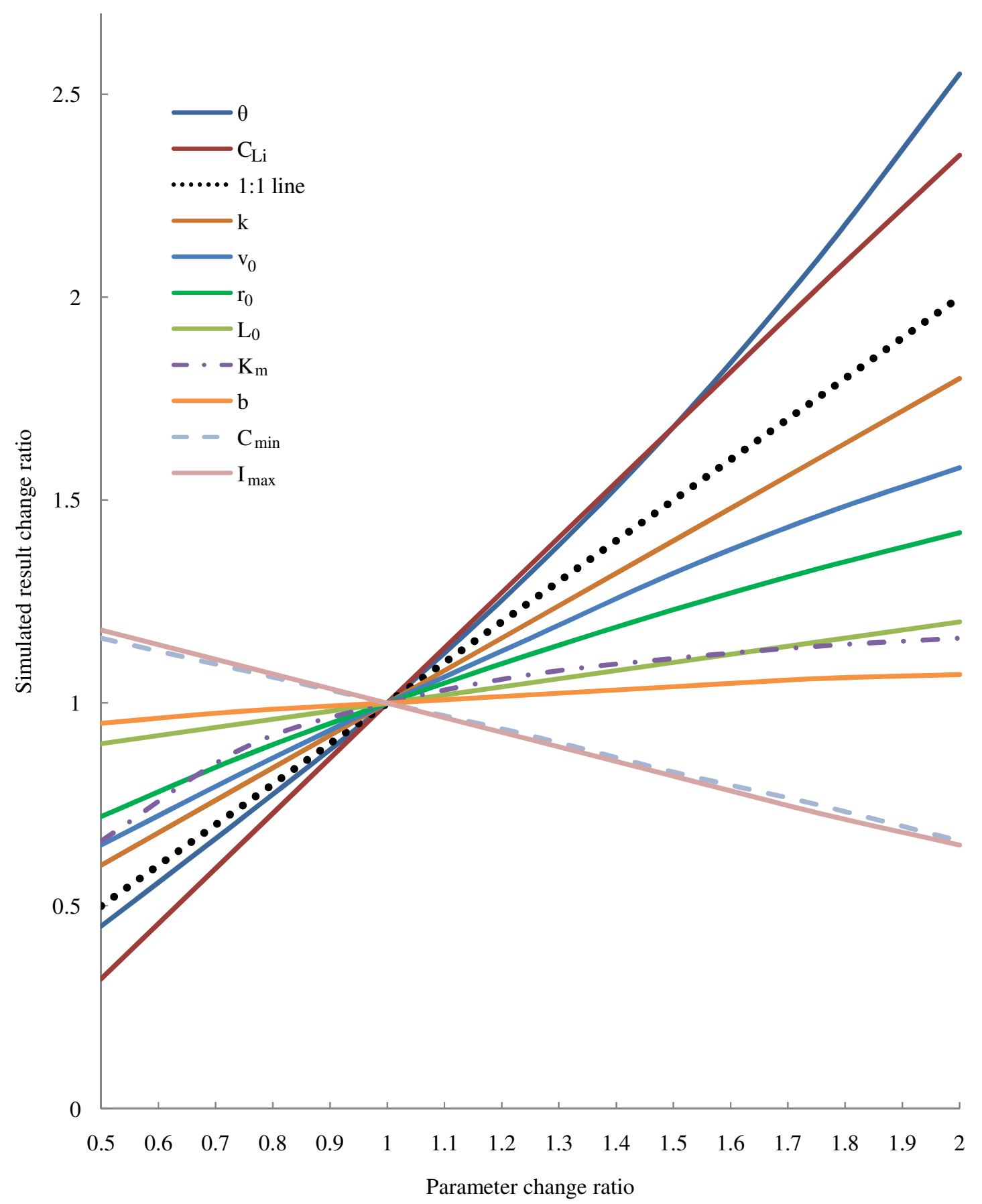

Figure 4. One dimensional sensitivity analysis using SSAND with potassium uptake data for loblolly pine seedlings from Kelly et al. (1992) and the diffusion coefficient of potassium in water at $25^{\circ} \mathrm{C}$ taken from the Parsons (1959). 


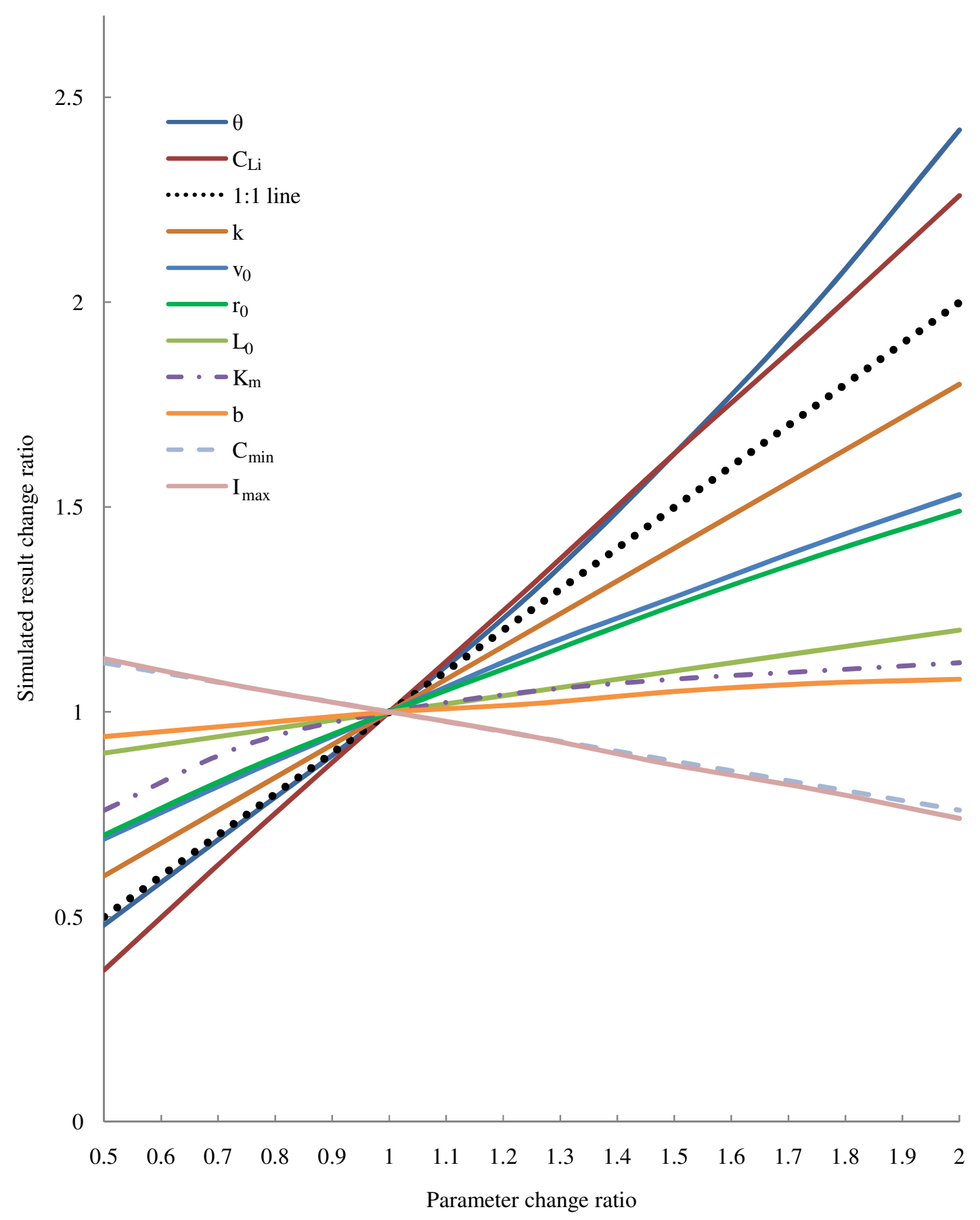

Figure 5. One dimensional sensitivity analysis using PCATS with potassium uptake data for loblolly pine seedlings from Kelly et al. (1992) and the diffusion coefficient of potassium in water at $25^{\circ} \mathrm{C}$ taken from the Parsons (1959). 


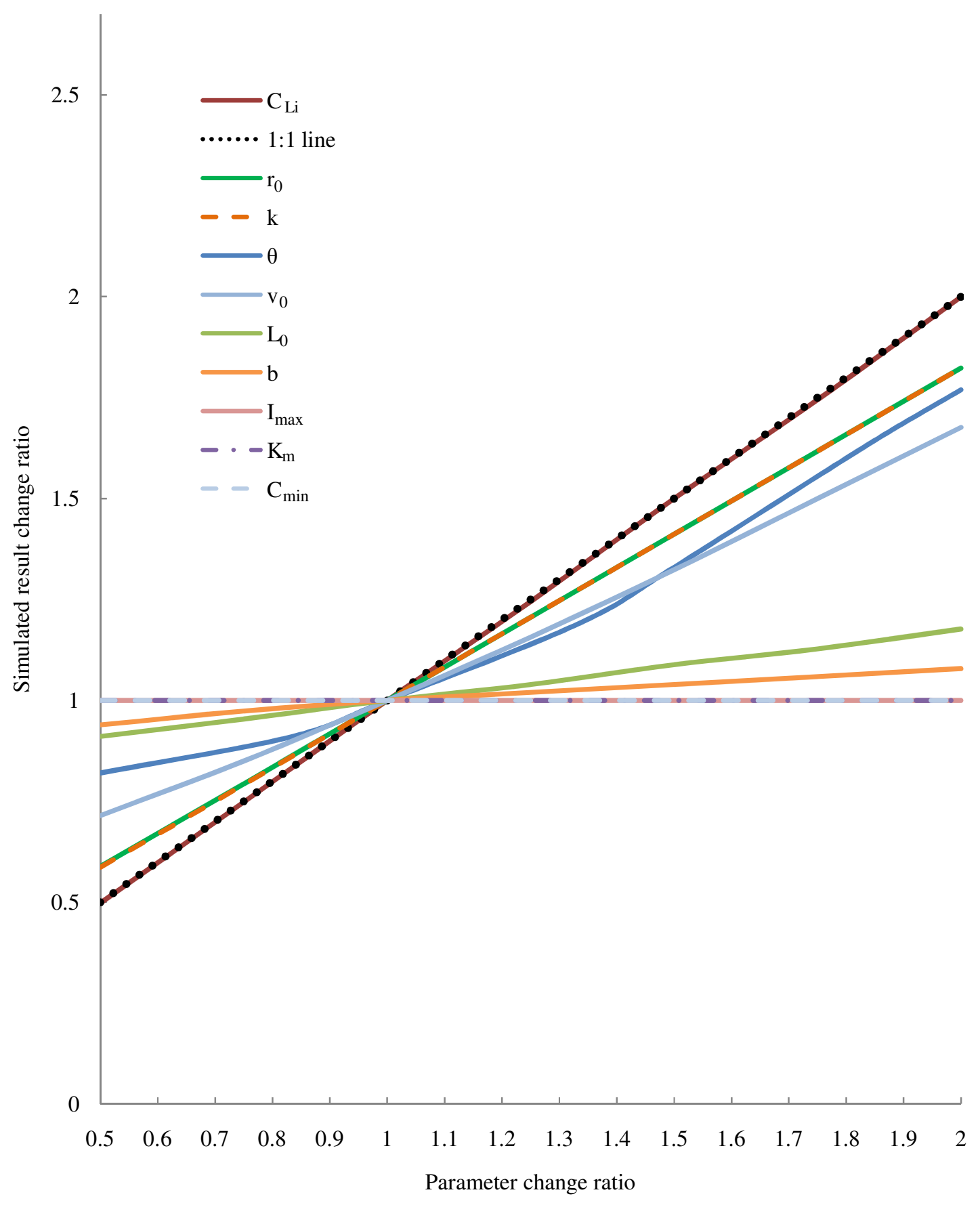

Figure 6. One dimensional sensitivity analysis using NST 3.0 with potassium uptake data for loblolly pine seedlings from Kelly et al. (1992) and the diffusion coefficient of potassium in water at $25^{\circ} \mathrm{C}$ taken from the Parsons (1959). 
2 harvests and 16 simulations. The slope of the line representing $I_{\max }$ in the sensitivity analysis of ammonium uptake at the second harvest on both soils, and of potassium uptake in the second harvest on one of the soils, were slightly negative. Unfortunately the author did not discuss this phenomenon and summarized parameter values regardless of soil type and harvests such that it is difficult to explore further with their data. Because the negative influence of $I_{\max }$ in the Singh (2008) study was found at the second harvest when soil nutrients were depleted, and the most influential parameters in the one dimensional sensitivity analysis were related to soil properties, we suspect that the uptake process was limited by soil supply of nutrients and it seems that the negative influence of $I_{\max }$ is related to a limited supply of nutrients by the soil.

To explore this phenomenon, we examined the effects of $\mathrm{I}_{\max }$ on uptake simulation with artificial datasets. In these data sets, root growth rate were set as $39.3 \mathrm{~cm} \mathrm{day}^{-1}$, and volumetric soil moisture was set as 0.4 (see multiple dimensional sensitivity analysis), so that they are not limiting soil supply or plant uptake process. The value of $\mathrm{C}_{\mathrm{Li}}$ was varied linearly at 5 levels, ranging from 0.028 to $8.54 \mu \mathrm{mol} \mathrm{ml}^{-1}$. In this case, we assume the nutrient supply of the soil increases as $\mathrm{C}_{\mathrm{Li}}$ increases. $\mathrm{I}_{\max }$ values for potassium uptake by loblolly and slash pine taken from the literature (Van Rees et al. 1990; Kelly et al. 1992; Kelly et al. 1995) range from 1.4E-6 to $3.65 \mathrm{E}-6 \mu \mathrm{mol} \mathrm{cm} \mathrm{s}^{-2}$. Because the actual $\mathrm{I}_{\max }$ may be very different, five levels of $\mathrm{I}_{\max }, 1.4 \mathrm{E}-7$, $1.4 \mathrm{E}-6,3.65 \mathrm{E}-6,1.4 \mathrm{E}-5$, and $1.4 \mathrm{E}-4 \mu \mathrm{mol} \mathrm{cm} \mathrm{s}^{-2} \mathrm{~s}^{-1}$, were used in order to get a comprehensive understanding of model behavior.

The results of this analysis are shown in Figure 7 . When $\mathrm{C}_{\mathrm{Li}}$ was equal to $0.028 \mu \mathrm{mol} \mathrm{ml}{ }^{-1}$, uptake simulated by SSAND was significantly lower than that of NST 3.0. The prediction by SSAND increased as $\mathrm{I}_{\max }$ increased from $1.4 \mathrm{E}-7$ to $1.4 \mathrm{E}-6 \mu \mathrm{mol} \mathrm{cm} \mathrm{s}^{-2} \mathrm{~s}^{-1}$, and then dropped as $I_{\max }$ increased further, while the prediction of NST 3.0 increased as $I_{\max }$ increased. Thus the pattern of simulated uptake by SSAND as $\mathrm{I}_{\max }$ increased shows a bell shape, compared to an exponential shaped curve by NST 3.0. When $\mathrm{C}_{\mathrm{Li}}$ was increased to $2.156 \mu \mathrm{mol} \mathrm{ml}^{-1}$, both models had similar predictions and patterns before $I_{\max }$ reached $1.4 \mathrm{E}-5 \mu \mathrm{mol} \mathrm{cm} \mathrm{cm}^{-1}$. The prediction of NST 3.0 still increased as $I_{\max }$ increased, while the prediction by SSAND dropped when $I_{\max }$ increased from $1.4 \mathrm{E}-5$ to $1.4 \mathrm{E}-4 \mu \mathrm{mol} \mathrm{cm} \mathrm{cm}^{-2} \mathrm{~s}^{-1}$. The patterns of model behavior under different levels of $\mathrm{C}_{\mathrm{Li}}$ higher than $4.284 \mu \mathrm{mol} \mathrm{ml}{ }^{-1}$ were similar. The predictions of both models were close and increased as $I_{\max }$ increased when $I_{\max }$ ranged from $1.4 \mathrm{E}-7$ to $1.4 \mathrm{E}-5 \mu \mathrm{mol} \mathrm{cm}{ }^{-2} \mathrm{~s}^{-1}$. The 

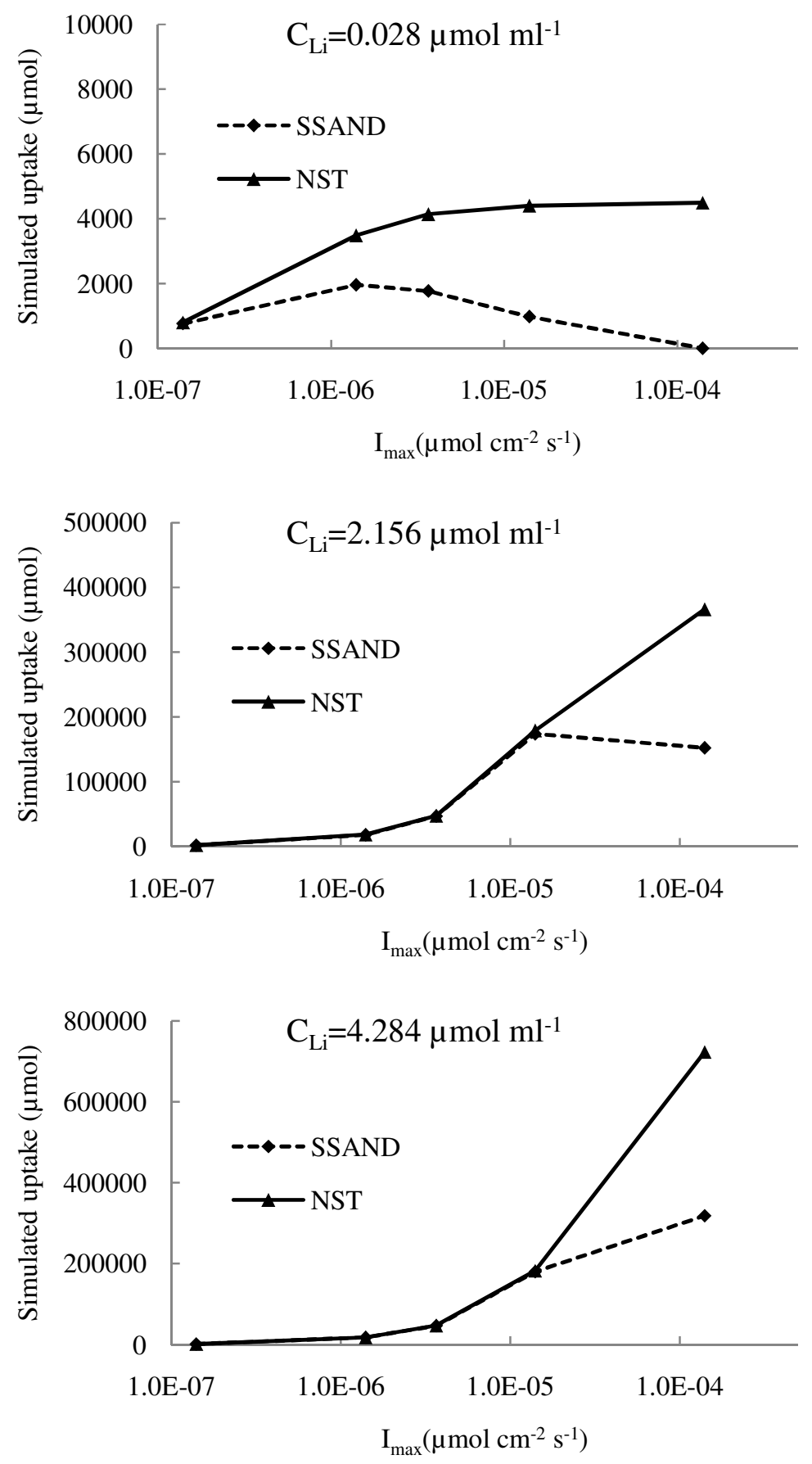

Figure 7. Simulated potassium uptake by SSAND and NST 3.0 at five levels of $\mathrm{I}_{\max }$ and three levels of $\mathrm{C}_{\mathrm{Li}}$. For these simulations root growth rate and volumetric soil moisture have been set to $39.3 \mathrm{~cm} \mathrm{day}^{-1}$ and 0.4 respectively. Other parameter values remained as listed in Table 6 for loblolly pine (Kelly et al. 1992). 
prediction of SSAND was lower than that of NST 3.0 when $\mathrm{I}_{\max }$ was equal to $1.4 \mathrm{E}-4 \mu \mathrm{mol} \mathrm{cm}{ }^{-2}$ $\mathrm{s}^{-1}$. Therefore, the behavior of SSAND is influenced by levels of $\mathrm{C}_{\mathrm{Li}}$, which indicates the ability of the soil to supply nutrients in our assumption. Our suspicion that the negative influence of $I_{\max }$ on SSAND simulation relates to the low nutrient supply by the soil is supported.

Previous studies with transient state models with a numerical solution have not reported a negative influence of $I_{\max }$ in the sensitivity analysis (Van Rees et al. 1990; Teo et al. 1992; Sadana and Claassen 1999; Sadana and Claassen 2000; Sterckeman et al. 2004; Gill et al. 2005; Comerford et al. 2006). In addition, the graphical representation in the multiple dimensional sensitivity analysis of a simplified steady state model by Williams and Yanai (1996) did not show a negative response in simulated uptake when $\mathrm{I}_{\max }$ increased. According to the MichaelisMenten uptake kinetics equation, nutrient influx into roots is positively related to $I_{\max }$. Because nutrient uptake by plants is the accumulation of influx over time and root surface area, it is illogical to think that increased $\mathrm{I}_{\max }$ would lead to a decrease in uptake. Therefore, we examined the key equation of the steady state model.

If $\mathrm{A}$ is used to represent $2 \pi r_{0} L_{v} \Delta t$, and B for $\left(\frac{2}{\left.2-\frac{r_{0} v_{0}}{b D}\right)} \frac{\left(\frac{r_{1}}{r_{0}}\right)^{\left(2-\frac{r_{0} v_{0}}{b D}\right)}-1}{\left(\frac{r_{1}}{r_{0}}\right)^{2}-1}\right.$, then the key equation 8 of the steady state model can be rewritten as

$$
\Delta U=A \alpha \frac{C_{a v} v_{0}}{\alpha+B\left(v_{0}-\alpha\right)}
$$

If $\mathrm{D}$ is used to represent $\frac{1}{K_{m}+C_{L 0}-C_{m i n}}$, then equation 9 can be rewritten as

$$
\alpha=D * I_{\max }
$$

Then

$$
\Delta U=\frac{A C_{a v} v_{0} I_{\max }}{\frac{B v_{0}}{D}+I_{\max }(1-B)}
$$

The partial derivative of $\Delta \mathrm{U}$ with respect to $\mathrm{I}_{\max }$ is

$$
\partial \Delta U / \partial I_{\max }=\frac{A B C_{a v} v_{0}^{2}}{D\left[\frac{B v_{0}}{D}+I_{\max }(1-B)\right]^{2}}
$$


When $\left(2-\frac{r_{0} v_{0}}{b D}\right)>0, \frac{\left(\frac{r_{1}}{r_{0}}\right)^{\left(2-\frac{r_{0} v_{0}}{b D}\right)}-1}{\left(\frac{r_{1}}{r_{0}}\right)^{2}-1}>0$ because $r_{1}>r_{0}$, and $\left(\frac{2}{2-\frac{r_{0} v_{0}}{b D}}\right)>0$. Therefore $B=\left(\frac{2}{2-\frac{r_{0} v_{0}}{b D}}\right) \frac{\left(\frac{r_{1}}{r_{0}}\right)^{\left(2-\frac{r_{0} v_{0}}{b D}\right)}-1}{\left(\frac{r_{1}}{r_{0}}\right)^{2}-1}>0$. When $\left(2-\frac{r_{0} v_{0}}{b D}\right)<0, \frac{\left(\frac{r_{1}}{r_{0}}\right)^{\left(2-\frac{r_{0} v_{0}}{b D}\right)}-1}{\left(\frac{r_{1}}{r_{0}}\right)^{2}-1}<0$ and $\left(\frac{2}{2-\frac{r_{0} v_{0}}{b D}}\right)<0$.

Therefore B is positive as well. Because $A=2 \pi r_{0} L_{v} \Delta t>0, D=\frac{1}{K_{m}+C_{L 0}-C_{\min }}>0, C_{a v}>0$, $B>0$, the partial derivative $\partial \Delta U / \partial I_{\max }$ (equation 18) is always positive, indicating that the function $\Delta U$ is monotonically increasing. That is, $\Delta U$ increases as $\mathrm{I}_{\max }$ increases. Since the total amount of nutrient uptake is obtained by summing $\Delta U$ at each time interval, the total amount of nutrient uptake calculated this way increases as $I_{\max }$ increases. The structure of SSAND and PCATS is more complex. But this simple calculation indicates that the negative influence by $\mathrm{I}_{\max }$ may be an artifact in the development of SSAND and PCATS.

Multiple dimensional sensitivity analysis

Figure 8 shows the relationship of simulated uptake to nutrient concentration in the soil solution $\left(\mathrm{C}_{\mathrm{Li}}\right)$, which increases along the $\mathrm{x}$-axis of each graph for both models. Each graph shows the results at a fixed level of root growth rate $(\mathrm{k})$. The $\mathrm{y}$-axis shows the simulated uptake in $\mu$ mol, while the $\mathrm{x}$-axis covers the range of $\mathrm{C}_{\mathrm{Li}}$ values, and on each graph there are five different lines, one for each level of volumetric soil moisture $(\theta)$. Thus each line represents the change in uptake at given $\theta$ and $\mathrm{k}$, with increasing $\mathrm{C}_{\mathrm{Li}}$. Each group of 5 graphs shows the results for a particular mechanistic model. The graphs are arranged such that $\mathrm{k}$ increases from the top row to the bottom. In general, uptake increases with $\mathrm{C}_{\mathrm{Li}}$ until it reaches its maximum at high $\mathrm{C}_{\mathrm{Li}}$. Comparison of the five lines on each graph reveals that with those with a higher $\theta$ show the strongest response to increasing $\mathrm{C}_{\mathrm{Li}}$. But at high levels of $\mathrm{C}_{\mathrm{Li}}$, an increased $\theta$ does not produce any differences in uptake. At low $\mathrm{C}_{\mathrm{Li}}$, the uptake is strongly reduced. Comparison of graphs in the same row shows the effect of changing $\mathrm{k}$. At low $\mathrm{k}$, the maximal simulated uptake is strongly reduced. The maximal simulated uptake increases proportionally as $\mathrm{k}$ increases. If the simulated uptake by both models is fitted to a linear regression, the regression equations are similar. For example, if $U_{M}(\mu \mathrm{mol})$ represents maximal simulated uptake, the equation for NST 3.0 is $U_{M}=433 k+1356$. 
SSAND
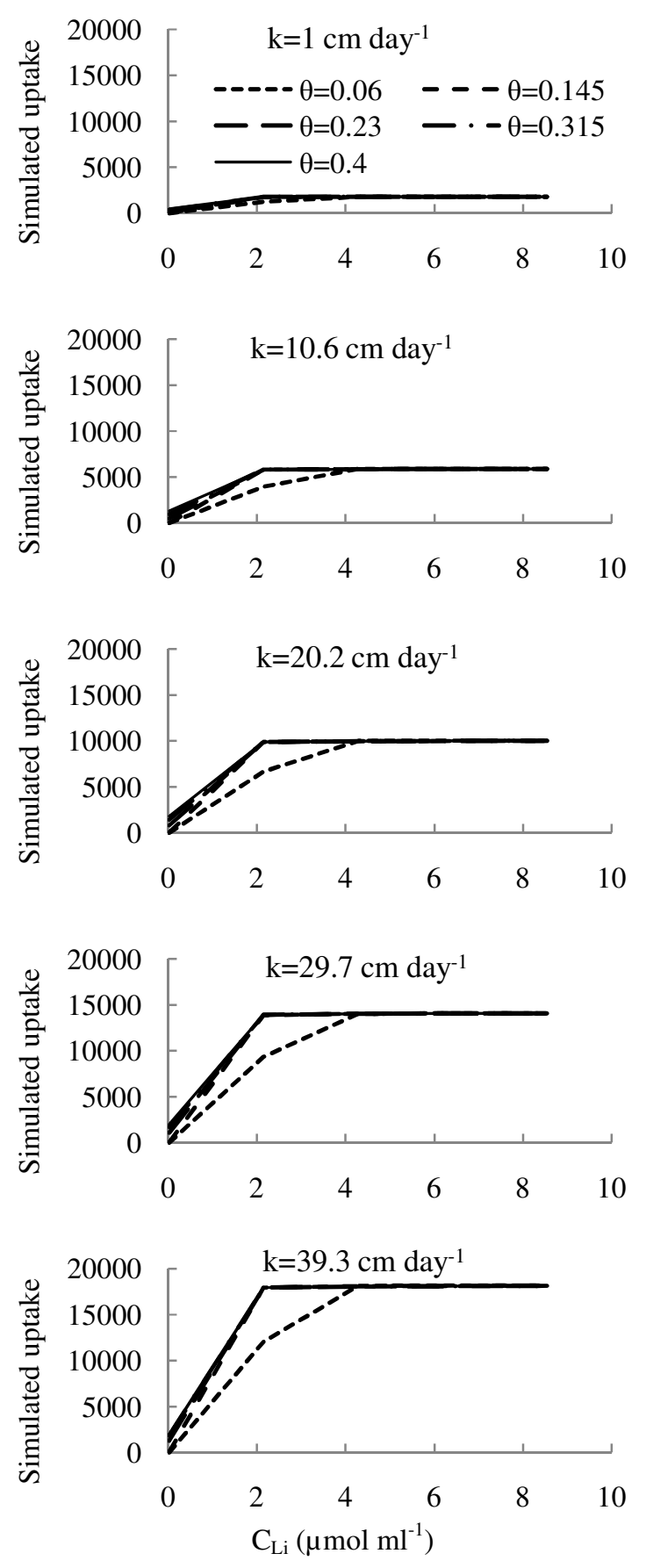

NST 3.0
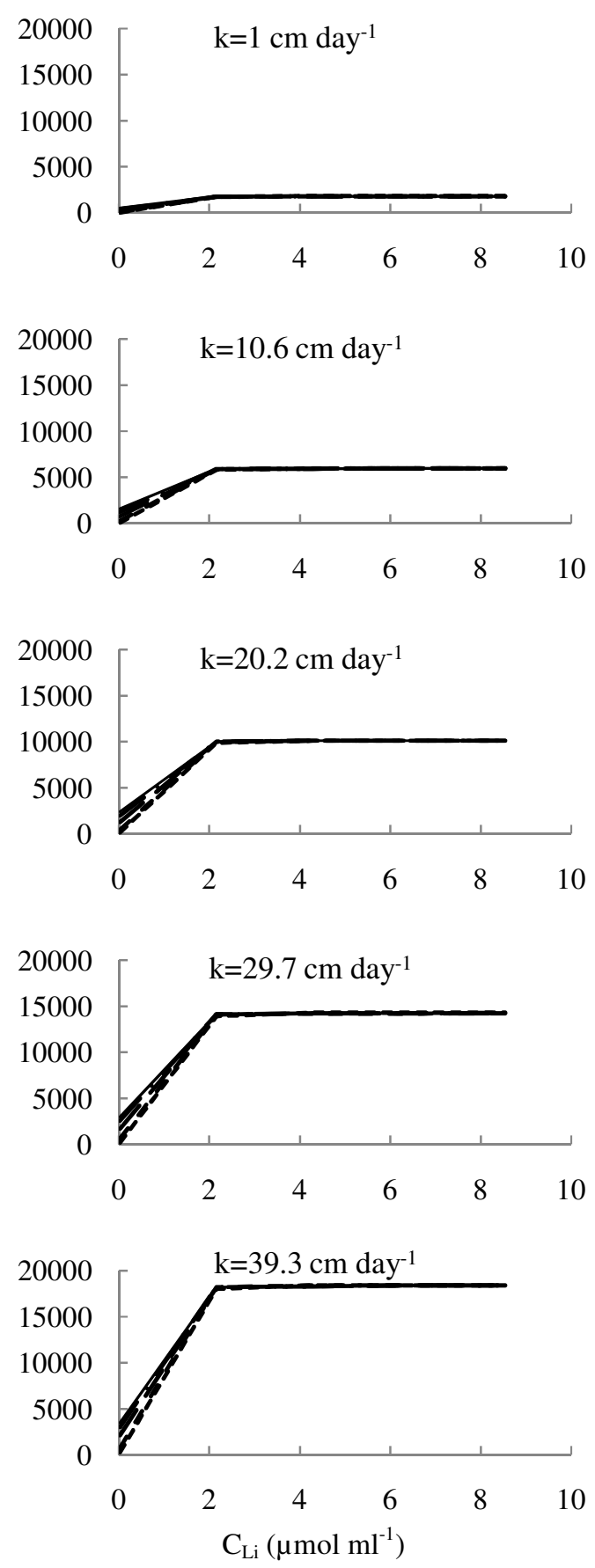

Figure 8. Response surface from a multiple dimensional sensitivity analysis of SSAND and NST 3.0 using five levels of potassium concentration in the soil solution $\left(\mathrm{C}_{\mathrm{Li}}\right)$, five levels of volumetric soil moisture $(\theta)$, and five levels of root growth rate $(\mathrm{k})$. Other parameter values remained as listed in Table 6 for loblolly pine (Kelly et al. 1992). The unit of simulated uptake is $\mu \mathrm{mol}$. 
Figure 9 shows the relationship of the same parameters used in the multiple dimensional sensitivity analysis depicted in Figure 8 in another way. In this case the $\mathrm{x}$-axis covers the range in $\theta$ values and each graph represents a change in the $C_{\mathrm{Li}}$ value. The graphs of simulated uptake at higher $\mathrm{C}_{\mathrm{Li}}$ values were not included in Figure 9 because for each $\mathrm{k}$, the simulated uptake at the higher $\mathrm{C}_{\mathrm{Li}}$ were the same as the uptake at $\mathrm{C}_{\mathrm{Li}}=2.156 \mu \mathrm{mol} \mathrm{ml}^{-1}$ with a high $\theta$. When $\mathrm{C}_{\mathrm{Li}}$ is low $\left(0.028 \mu \mathrm{mol} \mathrm{ml}^{-1}\right), \mathrm{SSAND}$ produces lower estimates than NST 3.0. For example, when $\mathrm{C}_{\mathrm{Li}}$ is $0.028 \mu \mathrm{mol} \mathrm{m} l^{-1}$ and $\theta$ is 0.06 , the predicted potassium uptake by SSAND is less than $0.1 \mu \mathrm{mol}$, while uptake simulated by NST 3.0 ranges from 24 to $258 \mu$ mol. When $\mathrm{C}_{\mathrm{Li}}$ is increased to 2.156 $\mu \mathrm{mol} \mathrm{ml}{ }^{-1}$, the increase in $\theta$ did not lead to a significant change in simulated uptake by NST 3.0, but the uptake simulated by SSAND is significantly reduced at low $\theta$ (Figures 8 and 9). It seems that SSAND is more sensitive to $\theta$, as was indicated in the one dimensional sensitivity analysis as well. However, the multiple dimensional sensitivity analysis also indicates the influence of $\theta$ on the SSAND simulation is only valid when $\mathrm{C}_{\mathrm{Li}}$ is low (Figure 9).

Because the transient state model with a numerical solution is assumed to be more accurate than the steady state model (Smethurst and Comerford 1993b; Smethurst et al. 2004), the performance of SSAND can be evaluated by comparing its simulated results with those of NST 3.0 in our multiple dimensional sensitivity analysis. As shown in Figure 9, the predicted uptake by SSAND is lower than that of NST 3.0 before the simulations reach their maximums (an example is given in Figure 10). Given this underestimate, and the inability of SSAND to predict phosphorus uptake in the hybrid poplar study, it is suspected that SSAND is less able to predict uptake accurately when the supply of nutrients by the soil cannot meet the plant's needs as defined by the uptake kinetics parameters.

\section{Conclusions}

In summary, NST 3.0, SSAND, and PCATS differ both in predictive accuracy and model behavior. PCATS successfully predicted nitrate uptake, NST 3.0 predicted phosphorus uptake well, while SSAND underpredicted all nutrient uptake severely. Results were also diverse, indicating the need of reconsideration of the assumptions and solutions of the two mechanistic model categories. Although NST 3.0 and PCATS performed relatively well with some runs, the model predictions of the others failed to match the observation. The underestimates of many of 
SSAND
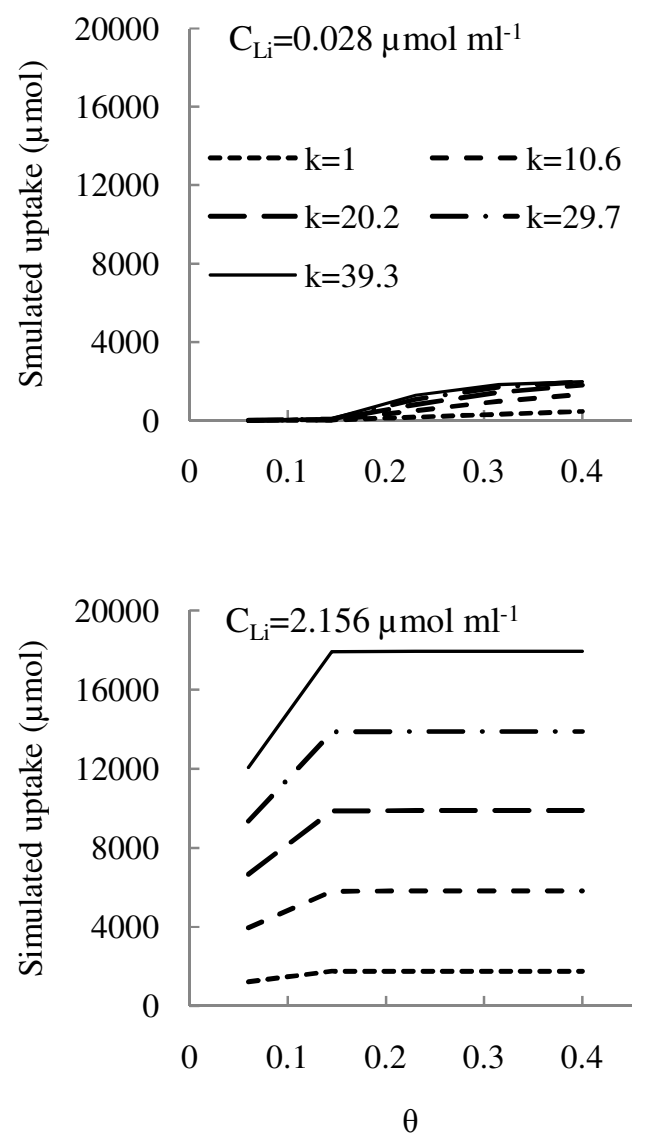

NST 3.0
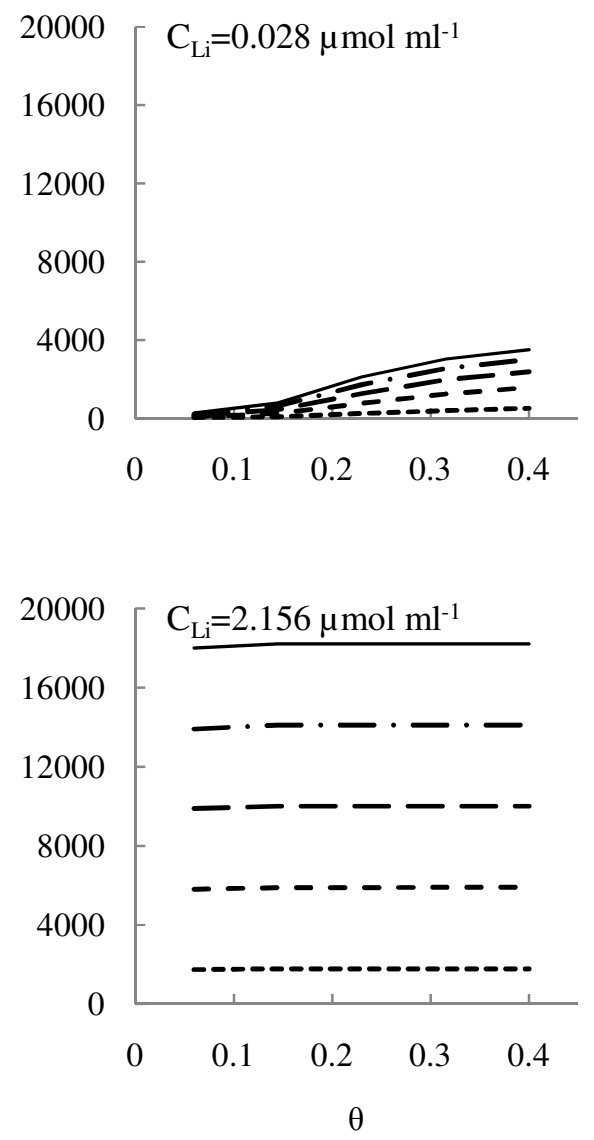

Figure 9. Response surface from a multiple dimensional sensitivity analysis of SSAND and NST 3.0 using two levels of potassium concentration in the soil solution $\left(\mathrm{C}_{\mathrm{Li}}\right)$, five levels of volumetric soil moisture $(\theta)$, and five levels of root growth rate $(\mathrm{k})$ with $\mathrm{cm} \mathrm{day}^{-1}$ as the units. Other parameter values remained as listed in Table 6 for loblolly pine (Kelly et al. 1992). 


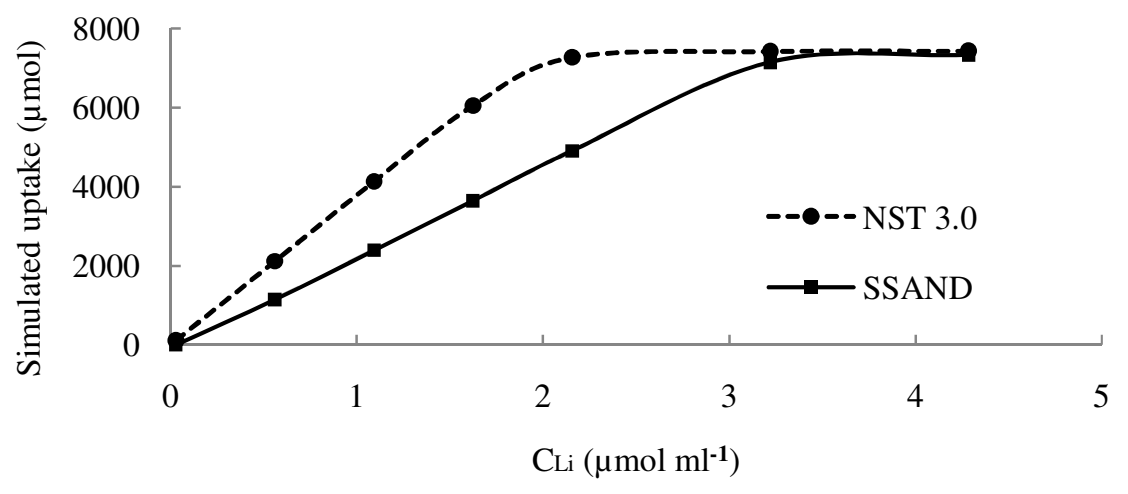

Figure 10. Simulated potassium uptake by SSAND and NST 3.0 with data taken from Kelly et al. (1992). The simulation was conducted with nutrient concentration in the soil solution $\left(\mathrm{C}_{\mathrm{Li}}\right)$ changing from 0.028 to $4.284 \mu \mathrm{mol} \mathrm{ml}^{-1}$ while keeping other parameters unchanged. 
the runs may be the results of running simulations without including the nutrient uptake by mycorrhizaes. But this alone cannot explain some successful simulations. Therefore, further studies that can produce representative datasets to evaluate the predictive accuracy against observed values for each model are needed for future model evaluation.

Both types of sensitivity analyses indicate that soil moisture $(\theta)$ plays an important role in uptake simulation when the nutrient concentration in the soil solution $\left(\mathrm{C}_{\mathrm{Li}}\right)$ is low. This has not been noted in previous studies. Under low-nutrient-supply scenarios, $\mathrm{I}_{\max }$ can influence the predictions of SSAND and PCATS negatively, and the uptake predictions of SSAND are generally lower than those of NST 3.0. We suspect that these are artifacts of the steady state models and further studies are needed to improve their ability to represent nutrient uptake under low-nutrient-supply scenarios.

In the process of soil exploration and nutrient uptake by plant roots, the influence of rhizospheric effects such as differences in rhizosphere $\mathrm{pH}$ and redox potential are important (Gillespie and Pope 1990; Marschner 1995). The three mechanistic nutrient uptake models do not include routines to describe such subprocesses except for the effects of mycorrhizaes. Because these effects are probably not negligible when the models are applied to longer growth periods and lower soil nutrient supply situations that are more typical of woody species, further studies to incorporate important rhizospheric effects other than mycorrhizae are suggested. 


\section{Literature Cited}

Baldwin, J. P., P. H. Nye and P. B. Tinker. 1973. Uptake of solutes by multiple root systems from soil III - a model for calculating the solute uptake by a randomly dispersed root system developing in a finite volume of soil. Plant and Soil 38: 621635.

Barber, S. A. 1995. Soil nutrient bioavailability: a mechanistic approach. 2nd edition. John Wiley \& Sons, Inc., New York.

Barber, S. A. and J. H. Cushman 1981. Nitrogen uptake model for agronomic crops. p. 382-409 in I. K. Iskandar (ed.). Modeling waste water renovation-land treatment: Wiley-Interscience, New York.

Bouldin, D. R. 1961. Mathematical description of diffusion processes in the soil-plant system. Soil Science Society of America Proceedings 25: 476-480.

Claassen, N. and S. A. Barber. 1976. Simulation model for nutrient uptake from soil by a growing plant root system. Agronomy Journal 68: 961-964.

Claassen, N. and B. Steingrobe 1999. Mechanistic simulation models for a better understanding of nutrient uptake from soil. p. 327-367 In Z. Rengel (ed.). Mineral nutrition of crops: fundamental mechanisms and implications. Food Products Press, New York.

Claassen, N., K. M. Syring and A. Jungk. 1986. Verification of a mathematical-model by simulating potassium uptake from soil. Plant and Soil 95: 209-220.

Comerford, N. B., W. P. Cropper, Jr., L. Hua, P. J. Smethurst, K. C. J. Van Rees, E. J. Jokela and F. Adams. 2006. Soil Supply and Nutrient Demand (SSAND): a general nutrient uptake model and an example of its application to forest management. Canadian Journal of Soil Science 86: 655-673.

Cushman, J. H. 1979a. An analytical solution to solute transport near root surfaces for low initial concentration: I. Equations' development. Soil Science Society of America Journal 43: 1087-1090.

Cushman, J. H. 1979b. An analytical solution to solute transport near root surfaces for low initial concentration: II. Applications. Soil Science Society of America Journal 43: 1090-1095.

Edwards, O. W. and E. O. Huffman. 1959. Diffusion of aqueous solutions of phosphoric acid at $25^{\circ}$. Journal of Physical Chemistry 63: 1830-1833.

Gill, A. A. S., U. S. Sadana and S. Debasmita. 2005. Phosphorus influx and root-shoot relations as indicators of phosphorus efficiency of different crops. Communications in Soil Science and Plant Analysis 36: 2315-2327. 
Gillespie, A. R. and P. E. Pope. 1990. Rhizosphere acidification increases phosphorus recovery of black locust: II. Model predictions and measured recovery. Soil Science Society of America Journal 54: 538-541.

Itoh, S. and S. A. Barber. 1983. A numerical solution of whole plant nutrient uptake for soil-root systems with root hairs. Plant and Soil 70: 403-413.

Kelly, J. M., S. A. Barber and G. S. Edwards. 1992. Modelling magnesium, phosphorus, and potassium uptake by loblolly pine seedlings using a Barber-Cushman approach. Plant and Soil 139: 209-218.

Kelly, J. M., A. H. Chappelka and B. G. Lockaby. 1995. Measured and estimated parameters for a model of nutrient uptake by trees. New Zealand Journal of Forestry Science 24: 213-225.

Kelly, J. M. and T. Ericsson. 2003. Assessing the nutrition of juvenile hybrid poplar using a steady state technque and a mechanistic model. Forest Ecology and Management 180: 249-260.

Kelly, J. M. and J. K. Kelly. 2001. Phosphorus and potssium uptake kinetics in red maple seedlings. Forest Science 47: 397-402.

Kelly, J. M., J. D. Scarbrough and P. A. Mays. 2001. Hardwood seedling root and nutrient parameters for a model of nutrient uptake. Journal of Environmental Quality 30: 427-439.

Kovar, J. L. and S. A. Barber. 1990. Potassium supply characteristics of thirty-three soils as influenced by seven rates of potassium. Soil Science Society of America Journal 54: 1356-1361.

Marschner, H. 1995. Mineral nutrition of higher plants. 2nd edition. Academic Press, London.

Nye, P. H. and F. H. C. Marriott. 1969. A theoretical study of the distribution of substances around roots resulting from simultaneous diffusion and mass flow. Plant and Soil 30: 459-472.

Nye, P. H. and J. A. Spiers. 1964. Simultaneous diffusion and mass flow to plant roots. p. 535-541 In (editors missing) Transactions : 8th International Congress of Soil Science, Bucharest, Romania, 31 Aug. -9 Sep. 1964. Publishing House of the Academy of the Socialist Republic of Romania, Rompresfilatelia, Bucharest.

Nye, P. H. and P. B. Tinker. 1977. Solute movement in the soil-root system. University of California Press, Berkeley and Los Angeles.

Oates, K. and S. A. Barber. 1987. NUTRIENT UPTAKE: a microcomputer program to predict nutrient absorption from soil by roots. Journal of Agronomic Education 16: 65-68. 
Olsen, S. R., W. D. Kemper and R. D. Jackson. 1962. Phosphate diffusion to plant roots. Soil Science Society of America Proceedings 26: 222-227.

Parsons, R. 1959. Handbook of electro-chemical constants. Academic Press, New York.

Pypers, P., J. Delrue, J. Diels, E. Smolders and R. Merckx. 2006. Phosphorus intensity determines short-term P uptake by pigeon pea (Cajanus cajan L.) grown in soils with differing P buffering capacity. Plant and Soil 284: 217-227.

Rengel, Z. 1993. Mechanistic simulation models of nutrient uptake: a review. Plant and Soil 152: 161-173.

Sadana, U. S. and N. Claassen. 1999. Potassium efficiency and dynamics in the rhizosphere of wheat, maize, and sugar beet evaluated by a mechanistic model. Journal of Plant Nutrition 22: 939-950.

Sadana, U. S. and N. Claassen. 2000. Manganese dynamics in the rhizosphere and Mn uptake by different crops evaluated by a mechanistic model. Plant and Soil 218: 233238.

Sadana, U. S., P. Sharma, O. Castañeda, D. Samal and N. Claassen. 2005. Manganese uptake and Mn efficiency of wheat cultivars are related to Mn-uptake kinetics and root growth. Journal of Plant Nutrition and Soil Science 168: 581-589.

Samal, D., U. S. Sadana and A. A. S. Gill. 2003. Mechanistic approach to study manganese influx and its depletion in the rhizosphere of wheat and raya. Communications in Soil Science and Plant Analysis 34: 3033-3044.

Satnam, S. and U. S. Sadana. 2002. Prediction of phosphorus uptake by wheat and its depletion in the rhizosphere using a mechanistic model. Journal of Plant Nutrition 25: 623-633.

Silberbush, M. and S. A. Barber. 1983. Sensitivity of simulated phosphorus uptake to parameters used by a mechanistic-mathematical model. Plant and Soil 74: 93-100.

Singh, B. 2008. Nutrient uptake by hybrid poplar in competition with weed species under growth chamber and field conditions using the soil supply and nutrient demand (SSAND) model. Ph.D. Dissertation University of Saskatchewan, Saskatoon, Canada.

Singh, S. and U. S. Sadana. 2002. Prediction of phosphorus uptake by wheat and its depletion in the rhizosphere using a mechanistic model. Journal of Plant Nutrition 25: 623-633.

Smethurst, P. J. and N. B. Comerford. 1993a. Potassium and phosphorus uptake by competing pine and grass: observations and model verification. Soil Science Society of America Journal 57: 1602-1610. 
Smethurst, P. J. and N. B. Comerford. 1993b. Simulating nutrient uptake by single or competing and contrasting root systems. Soil Science Society of America Journal 57: 1361-1367.

Smethurst, P. J., N. B. Comerford and D. G. Neary. 1993. Predicting the effects of weeds on $\mathrm{K}$ and $\mathrm{P}$ uptake by young slash pine on a Spodosol. Forest Ecology and Management 60: 27-39.

Smethurst, P. J., D. S. Mendham, M. Battaglia and R. Misra. 2004. Simultaneous prediction of nitrogen and phosphorus dynamics in a Eucalyptus nitens plantation using linked CABALA and PCATS models. p. 565-569 In N. M. G. Borralho (ed.) Eucalyptus in a changing world. Proceedings of an International Conference of the WP2.08.03 on Silviculture and Improvement of Eucalypts, Aveiro, Portugal, 11-15 October 2004. IUFRO, Aveiro, Portugal.

Steingrobe, B., N. Claassen and K. M. Syring. 2000. The effect of the function type for describing the soil buffer power on calculated ion transport to roots and nutrient uptake from the soil. Journal of Plant Nutrition and Soil Science-Zeitschrift Fur Pflanzenernahrung Und Bodenkunde 163: 459-465.

Sterckeman, T., J. Perriguey, M. Caël, C. Schwartz and J. L. Morel. 2004. Applying a mechanistic model to cadmium uptake by Zea mays and Thlaspi caerulescens: Consequences for the assessment of the soil quantity and capacity factors. Plant and Soil 262: 289-302.

Teo, Y. H., C. A. Beyrouty and E. E. Gbur. 1992. Evaluating a model for predicting nutrient uptake by rice during vegetative growth. Agronomy Journal 84: 1064-1070.

Tinker, P. B. and P. H. Nye. 2000. Solute movement in the rhizosphere. Oxford University Press, New York.

Van Rees, K. C. J., N. B. Comerford and W. W. Mcfee. 1990. Modelling potassium uptake by slash pine seedlings from low-potassium-supplying soils. Soil Science Society of America Journal 54: 1413-1421.

Van Rees, K. C. J. and N. B. Comerford. 1990. The role of woody roots of slash pine seedlings in water and potassium absorption. Canadian Journal of Forest Research 20: 1183-1191.

Williams, M. and R. D. Yanai. 1996. Multi-dimensional sensitivity analysis and ecological implications of a nutrient uptake model. Plant and Soil 180: 311-324.

Yanai, R. D. 1994. A steady-state model of nutrient uptake accounting for newly grown roots. Soil Science Society of America Journal 58: 1562-1571. 